ARTICLE

\title{
Preparation of $\mathrm{TiH}_{1.924}$ nanodots by liquid-phase exfoliation for enhanced sonodynamic cancer therapy
}

Fei Gong ${ }^{1}$, Liang Cheng ${ }^{1 凶}$, Nailin Yang ${ }^{1}$, Yuehan Gong ${ }^{1}$, Yanwen Ni ${ }^{1}$, Shang Bai ${ }^{1}$, Xianwen Wang (1) ${ }^{1}$, Muchao Chen ${ }^{1}$, Qian Chen ${ }^{1} \&$ Zhuang Liu (1) ${ }^{1 凶}$

Metal hydrides have been rarely used in biomedicine. Herein, we fabricate titanium hydride $\left(\mathrm{TiH}_{1.924}\right)$ nanodots from its powder form via the liquid-phase exfoliation, and apply these metal hydride nanodots for effective cancer treatment. The liquid-phase exfoliation is an effective method to synthesize these metal hydride nanomaterials, and its efficiency is determined by the matching of surface energy between the solvent and the metal hydrides. The obtained $\mathrm{TiH}_{1.924}$ nanodots can produce reactive oxygen species (ROS) under ultrasound, presenting a highly efficient sono-sensitizing effect. Meanwhile, $\mathrm{TiH}_{1.924}$ nanodots with strong near-infrared (NIR) absorbance can serve as a robust photothermal agent. By using the mild photothermal effect to enhance intra-tumoral blood flow and improve tumor oxygenation, a remarkable synergistic therapeutic effect is achieved in the combined photothermal-sonodynamic therapy. Importantly, most of these $\mathrm{TiH}_{1.924}$ nanodots can be cleared out from the body. This work presents the promises of functional metal hydride nanomaterials for biomedical applications.

\footnotetext{
${ }^{1}$ Institute of Functional Nano \& Soft Materials (FUNSOM), Jiangsu Key Laboratory for Carbon-Based Functional Materials and Devices, Soochow University, Suzhou 215123, China. ${ }^{凶}$ email: Icheng2@suda.edu.cn; zliu@suda.edu.cn
} 
S: onodynamic therapy (SDT) triggered by ultrasound (US) is a non-invasive therapeutic strategy that can be applied to treat deeply-seated tumors ${ }^{1-4}$. During SDT, sono-sensitizers are able to interact with surrounding oxygen and even water molecules to produce cytotoxic reactive oxygen species (ROS) to kill tumor cells ${ }^{2,4-7}$. However, the limitations of current sonosensitizers have substantially hindered the extensive clinical applications of SDT. Traditional organic sono-sensitizers (e.g., photofrin $^{8}$, phthalocyanine ${ }^{9}$, and chlorophyll derivative ${ }^{10}$ ), which are often derived from photo-sensitizers, often show phototoxicity toward the skin ${ }^{11,12}$. The most representative paradigm of inorganic sono-sensitizers is semiconductor titanium dioxide $\left(\mathrm{TiO}_{2}\right)^{13-15}$, whose quantum yield of US-triggered ROS generation, however, is relatively low due to the fast combination of the electron $\left(\mathrm{e}^{-}\right)$and holes $\left(\mathrm{h}^{+}\right)(50 \pm 30 \mathrm{~ns})^{16,17}$.

Titanium hydride $\left(\mathrm{TiH}_{1.924}\right)$ has been explored for applications in hydrogen storage ${ }^{18,19}$, and is frequently used as a foaming agent in the production of metallic foams (e.g., $\mathrm{Zn}, \mathrm{Al}$ foams $)^{20,21}$, as well as a raw material for producing highly purified titanium and titanium alloys ${ }^{22,23}$. Considering the unique valence status of $\mathrm{Ti}$ (containing $\mathrm{Ti}^{0}, \mathrm{Ti}^{2+}, \mathrm{Ti}^{3+}$, and $\mathrm{Ti}^{4+}$ ) in $\mathrm{TiH}_{1.924},{ }^{24}$ we hypothesize that it might be easily activated by external stimuli (e.g., light, ultrasound, and microwave) for applications in photocatalysis and sono-catalysis ${ }^{25,26}$. However, nano-structured $\mathrm{TiH}_{1.924}$ has not yet been synthesized to our best knowledge.

Liquid-phase exfoliation usually by sonicating bulk materials in appropriate solvents is a simple top-down route to produce various types of nanomaterials. In this work, we successfully exfoliate $\mathrm{TiH}_{1.924}$ powder into ultrasmall nanodots via the liquidphase exfoliation technology, and find that the surface energy plays an important role in the formation of the ultrasmall $\mathrm{TiH}_{1.924}$ nanodots. In addition, this liquid-phase exfoliation is an effective method to synthesize various types of metal hydride nanomaterials (e.g., $\mathrm{TiH}_{1.924}, \mathrm{ZrH}_{2}, \mathrm{CaH}_{2}$, and $\mathrm{HfH}_{1.983}$ ). Taking $\mathrm{TiH}_{1.924}$ nanodots for example, they have highly effective US-triggered ROS generation capability, which is superior to the sono-sensitizing effect of titanium dioxide $\left(\mathrm{TiO}_{2}\right)$, the classical inorganic sono-sensitizer, likely owing to the reduced bandgap in
$\mathrm{TiH}_{1.924}$. Moreover, these black $\mathrm{TiH}_{1.924}$ nanodots with strong near-infrared (NIR) absorption can also use as an excellent photothermal agent. Taking the advantage of mild photothermal effect to enhance intra-tumor blood flow and improve oxygen supply, a remarkably synergistic photothermal-sonodynamic therapeutic outcome has been achieved with $\mathrm{TiH}_{1.924}$ nanodots (Fig. 1). In a mouse tumor model, the complete tumor eradication without recurrence is achieved after intravenous injection of $\mathrm{TiH}_{1.924}$ nanodots and exposure of tumors to light and ultrasound, sequentially. Importantly, these $\mathrm{TiH}_{1.924}$ nanodots with ultra-small sizes show efficient body excretion and no appreciable toxicity to the treated animals. This work highlights the potential of metal hydride nanomaterials as physical stimuli-triggered nanoagents for cancer treatment.

\section{Results}

Preparation and characterization of $\mathrm{TiH}_{1.924}$ nanodots. Liquidphase exfoliation technology has been widely reported for the preparation of mono- or few-layered two-dimensional nanosheets $^{27-30}$. In this work, we unexpectedly found that metal hydrides powder could be easily exfoliated into nanodots using liquid-phase exfoliation technology in the presence of appropriate solvents (Fig. 2a). Taking $\mathrm{TiH}_{1.924}$ for example, we initially sonicated commercial $\mathrm{TiH}_{1.924}$ powder in a number of exfoliation solvents (Fig. 2a, b). Among these 13 solvents including water, glycerol, dimethyl sulfoxide/ $N$-methyl pyrrolidone (DMSO/NMP), DMSO, polyethylene glycol 200 (PEG 200), NMP, N,N-dimethylformamide (DMF)/NMP, pyridine, DMF, acetonitrile, tetrahydrofuran (THF), ethanol and acetone, 6 solvents of them (water, glycerol, acetonitrile, THF, ethanol, and acetone) showed no exfoliation effects to the $\mathrm{TiH}_{1.924}$ powder, while the other 7 solvents (DMSO/ NMP, DMSO, PEG 200, NMP, DMF/NMP, pyridine, and DMF) could efficiently exfoliate the $\mathrm{TiH}_{1.924}$ powder into small nanoparticles (Fig. 2b). The different exfoliation results might be attributed to the surface energy of these solvents (Fig. 2c ${ }^{27,31-33}$. For these 13 solvents, when the surface energy is too high $\left(\mathrm{H}_{2} \mathrm{O}\right.$, 72.7; glycerol, $63.4 \mathrm{~mJ} \mathrm{~m}^{-2}$ ) or too low (acetonitrile, 28.1; THF,

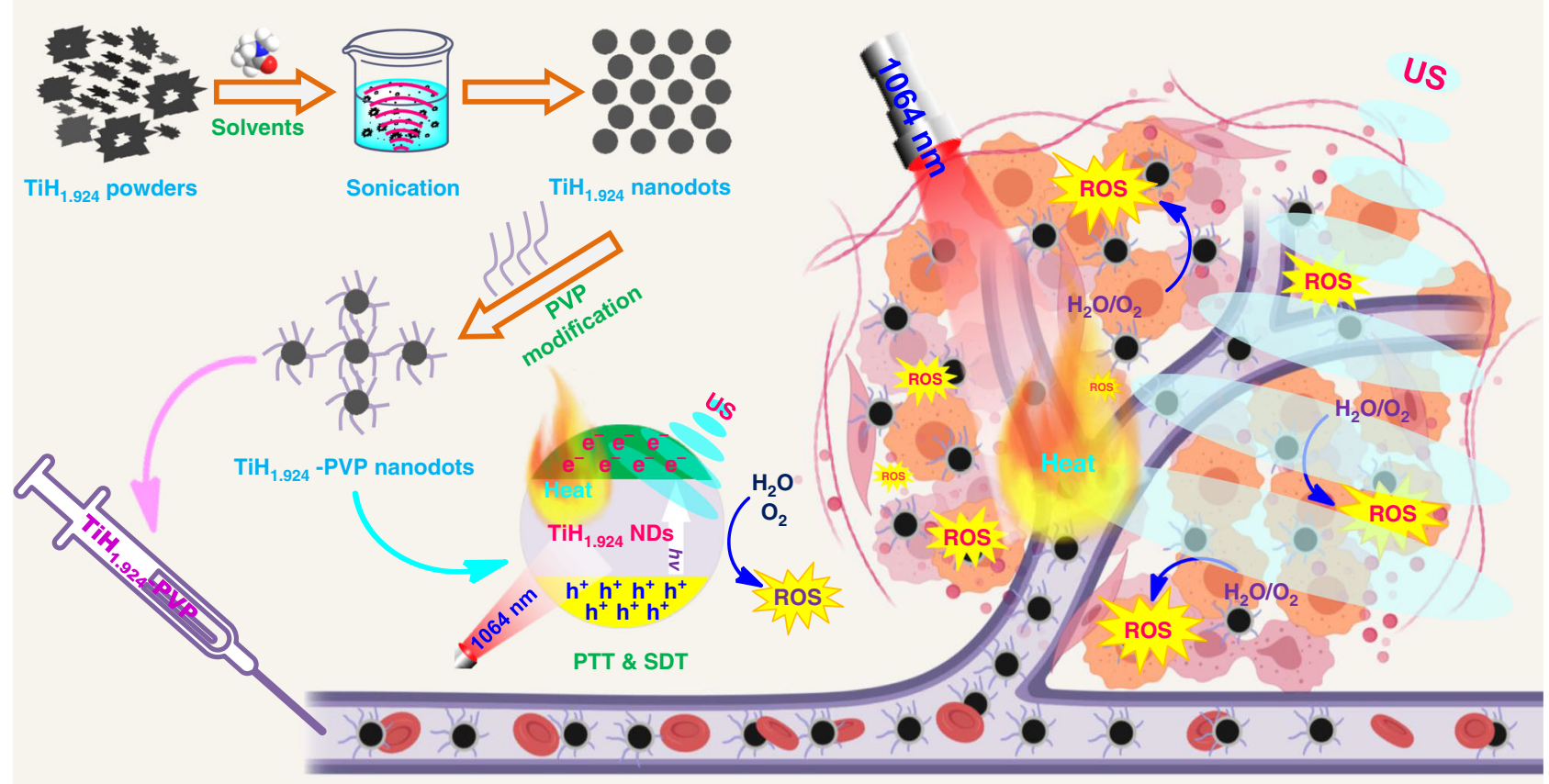

Fig. 1 The preparation and application of $\mathbf{T i H}_{\mathbf{1 . 9 2 4}}$ nanodot. Schematic illustration to show the preparation of $\mathrm{TiH}_{1.924}$ nanodots by liquid-phase exfoliation and their applications for combined photothermal-sonodynamic cancer therapy. 
a

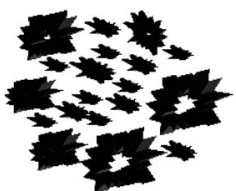

Powder
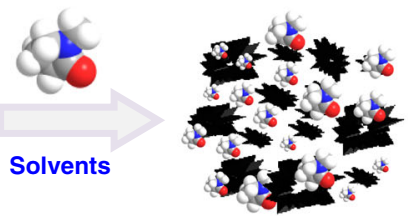

Dispersion

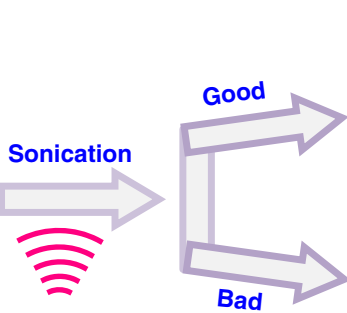

Completely exfoliated

b

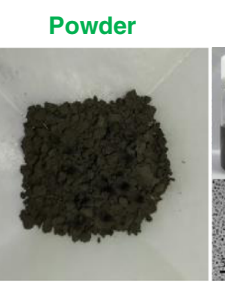

NMP

DMSO/NMP
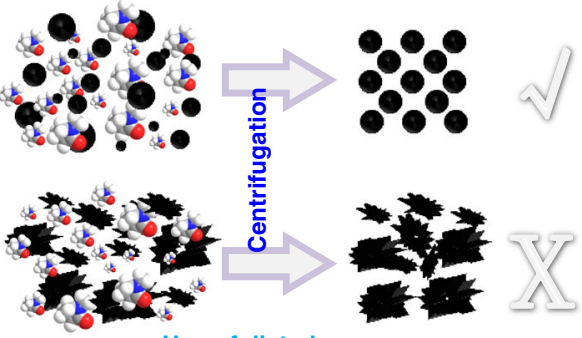

Un-exfoliated

$\mathrm{H}_{2} \mathrm{O}$

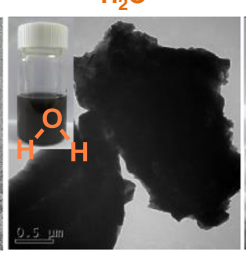

THF

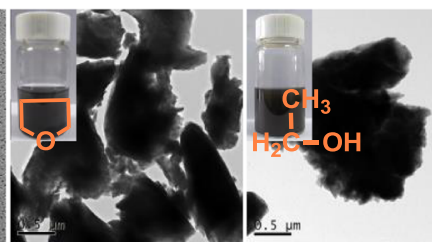

Glycerol

Ethanol
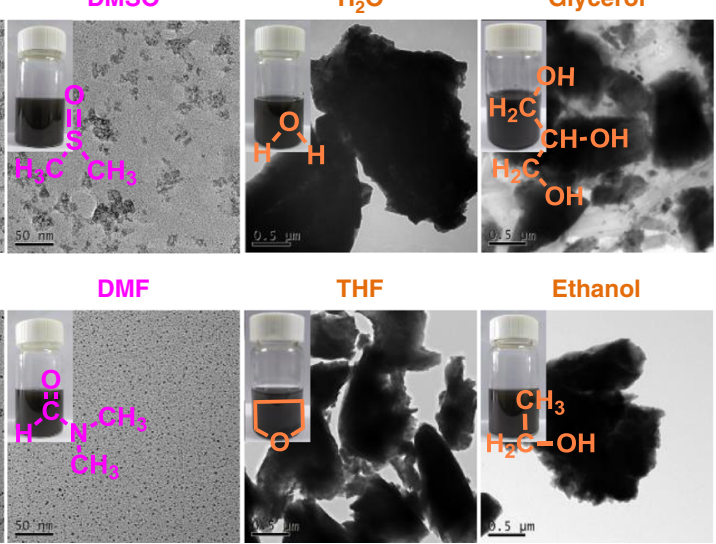
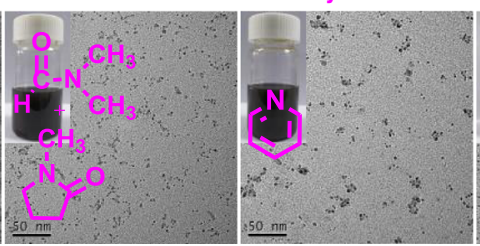

C
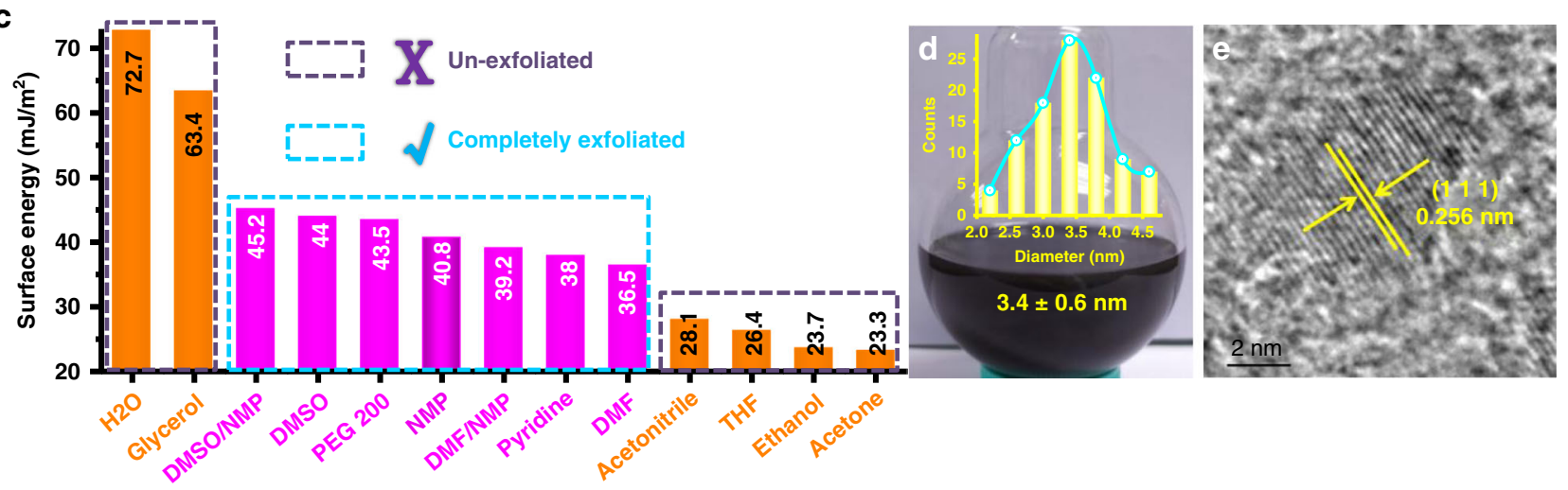

f

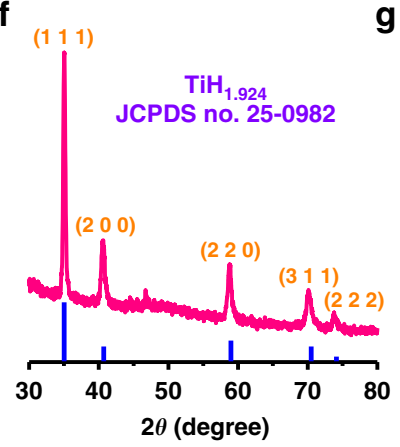

g

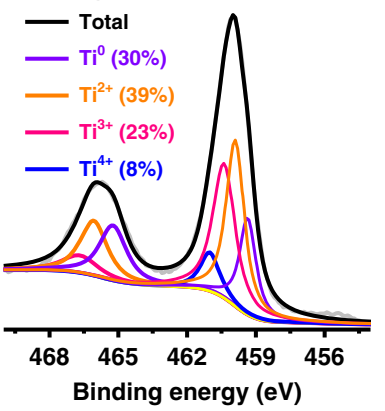

$\mathbf{h}$

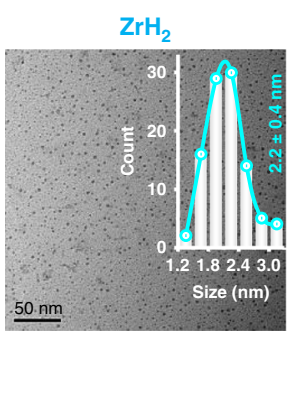

Acetonitrile

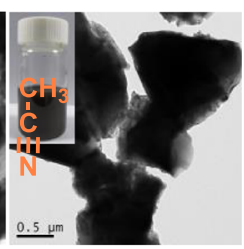

Acetone

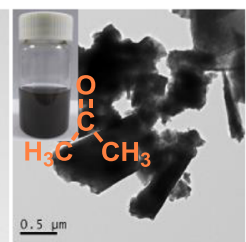

$\underline{0.5 \mu \mathrm{m}}$

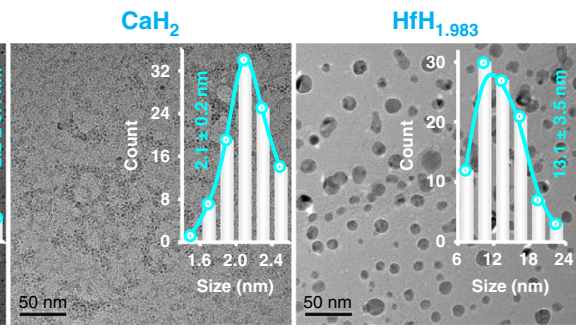

$\mathrm{CaH}_{2}$

Fig. 2 Preparation and characterization of $\mathbf{T i H}_{\mathbf{1 . 9 2 4}}$ nanodots. a Schematic illustration to show light-phase exfoliation to prepare $\mathrm{TiH} \mathrm{H}_{1.924}$ nanodots. $\mathbf{b} \mathrm{A}$ photograph of commercial $\mathrm{TiH}_{1.924}$ powder, the TEM images and corresponding photographs of exfoliated dispersions using various solvents $\left(\mathrm{H}_{2} \mathrm{O}\right.$, glycerol, dimethyl sulfoxide/N-methyl pyrrolidone (DMSO/NMP) DMSO/NMP, DMSO, polyethylene glycol 200 (PEG 200), NMP, N,N-dimethylformamide (DMF)/ NMP, pyridine, DMF, acetonitrile, tetrahydrofuran (THF), ethanol, and acetone) for $\mathrm{TiH}_{1.924}$ exfoliation. c The surface energies of various solvents used to exfoliate $\mathrm{TiH}_{1.924}$. d A photograph of exfoliated $\mathrm{TiH}_{1.924}$ nanodots in NMP. Inset is the particle-size distribution (PSD) of TiH $\mathrm{H}_{1.924} \mathrm{Hanodots}$ determined by the TEM image ( $n=100$ nanodots examined over TEM images). e High-resolution TEM (HRTEM) image of TiH ${ }_{1.924}$ nanodots. $\mathbf{f}$ XRD spectra of TiH $\mathrm{H}_{1.924}$ nanodots. g XPS spectra to show Ti $2 p$ peaks for the $\mathrm{TiH}_{1.924}$ nanodots sample. $\mathbf{h} \mathrm{TEM}$ images and PSD of $\mathrm{ZrH}_{2}$ nanodots, $\mathrm{CaH}_{2}$ nanodots, and $\mathrm{HfH}_{1.983}$ nanoparticles exfoliated in NMP ( $n=100$ nanomaterials examined over TEM images). A representative image of three biological replicates from each group is shown in $\mathbf{b}$, $\mathbf{e}$. 
26.3; ethanol, 23.7; acetone, $23.3 \mathrm{~mJ} \mathrm{~m}^{-2}$ ), $\mathrm{TiH}_{1.924}$ powder could not be effectively exfoliated. When the surface energy of the solvent (DMSO/NMP, 45.2; DMSO, 44; PEG 200, 43.5; NMP, 40.8; DMF/NMP, 39.2; pyridine, 38; DMF, $36.5 \mathrm{~mJ} \mathrm{~m}^{-2}$ ) reaches a range of $41 \pm 5 \mathrm{~mJ} \mathrm{~m}^{-2}$, successful exfoliation of the $\mathrm{TiH}_{1.924}$ powder into small nanoparticles could be achieved. Therefore, we proposed that the successful exfoliation might be owing to the matching of surface energy between the applied solvents and the $\mathrm{TiH}_{1.924}$ powder.

Among these 13 solvents, NMP offered excellent exfoliation efficiency and the obtained $\mathrm{TiH}_{1.924}$ nanodots showed very uniform sizes and morphology (Fig. 2b). Thus, we employed NMP as the representative solvent to investigate the liquid-phase exfoliation of $\mathrm{TiH}_{1.924}$ powder. After exfoliation of $\mathrm{TiH}_{1.924}$ powder by sonication in NMP for different periods of time (Supplementary Fig. 1A-C), we found that the intensities of the $\mathrm{X}$-ray diffraction (XRD) characteristic peaks decreased significantly by a time-dependent manner (Supplementary Fig. 1D). Particularly, after 20 min of ultrasonication, the $\mathrm{TiH}_{1.924}$ powder was entirely exfoliated into nanodots. Most importantly, this sample could be scaled-up to prepare large amounts of $\mathrm{TiH}_{1.924}$ nanodots with high quality, and the obtained $\mathrm{TiH}_{1.924}$ nanodots with an average diameter of $3.4 \pm 0.6 \mathrm{~nm}$ could be well dispersed in NMP (Fig. 2d). The high-resolution TEM (transmission electron microscope) determined the lattice spacing to be 0.256 nm (Fig. 2e), which could be assigned to the (llll) lattice plane of $\mathrm{TiH}_{1.924}$ (JCPDS No. 25-0982) (Fig. 2f) ${ }^{34}$. The energy dispersive spectrometer (EDS) spectrum also confirmed the existence of Ti elements (Supplementary Fig. 2). Based on the X-ray photoelectron spectroscopy (XPS, Supplementary Fig. 3), $\mathrm{Ti}$ with various valence states including $\mathrm{Ti}^{0}(30 \%), \mathrm{Ti}^{2+}(39 \%)$, $\mathrm{Ti}^{3+}(23 \%)$, and $\mathrm{Ti}^{4+}(8 \%)$ were found in the obtained $\mathrm{TiH}_{1.924}$ nanodots (Fig. $2 \mathrm{~g}$ ) ${ }^{24}$. Apart from the $\mathrm{TiH}_{1.924}$ powder, we also successfully exfoliated zirconium hydride $\left(\mathrm{ZrH}_{2}\right)$, calcium hydride $\left(\mathrm{CaH}_{2}\right)$, and hafnium hydride $\left(\mathrm{HfH}_{1.983}\right)$ powder using the liquid-phase exfoliation technology with the assistance of NMP (Fig. 2h, Supplementary Fig. 4). The obtained $\mathrm{ZrH}_{2}$ nanodots $(2.2 \pm 0.4 \mathrm{~nm}), \mathrm{CaH}_{2}$ nanodots $(2.1 \pm 0.2 \mathrm{~nm})$, and $\mathrm{HfH}_{1.983}$ nanoparticles $(13.1 \pm 3.5 \mathrm{~nm})$ all showed uniform morphology, suggesting that the liquid-phase exfoliation technology could be a simple and universal method to prepare various types of metal hydrides nanomaterials.

Sonodynamic and photothermal performance of $\mathrm{TiH}_{1.924}$ nanodots. The special valence structure of $\mathrm{TiH}_{1.924}$ nanodots indicates that they might be activated under US irradiation as a sono-sensitizer (Fig. 3a). Thus, to explore whether $\mathrm{TiH}_{1.924}$ nanodots could enhance sono-catalysis, 1,3-diphenylisobenzofuran (DPBF), a reactive oxide species (ROS) probe, was employed to detect the ROS generation by US-activated $\mathrm{TiH}_{1.924}$ nanodots. After mixing $\mathrm{TiH}_{1.924}$ nanodots with the DPBF probe, the UV-vis absorption spectrum of the mixture was monitored after different periods of ultrasound (US) irradiation (Fig. 3b, Supplementary Fig. 5). Undergoing a series of US irradiation time, the intensity of DPBF characteristic absorption peak at 420 $\mathrm{nm}$ showed significant decrease, suggesting the quenching of probe by the generated ROS. Compared with commercial $\mathrm{TiO}_{2}$ nanoparticles and untreated $\mathrm{TiH}_{1.924}$ powder, the exfoliated $\mathrm{TiH}_{1.924}$ nanodots exhibited a higher DPBF oxidation rate under the same US irradiation (Fig. 3c, Supplementary Fig. 6), indicating that $\mathrm{TiH}_{1.924}$ nanodots could serve as a stronger sonosensitizer than $\mathrm{TiO}_{2}$. In addition, $\mathrm{TiH}_{1.924}$ sono-sensitizers with higher exfoliation degrees showed better sonodynamic performance (Supplementary Fig. 7). Electron spin resonance (ESR) detection was also performed to compare the generated ROS $\left({ }^{1} \mathrm{O}_{2}, \cdot \mathrm{O}_{2}^{-}\right.$, and $\left.\cdot \mathrm{OH}\right)$ between $\mathrm{TiH}_{1.924}$ and $\mathrm{TiO}_{2}$ sono-sensitizer. (Fig. 3d, Supplementary Figs. 8 and 9). The characteristic peak intensities of the $\mathrm{TiH}_{1.924}$ plus US showed a great increase than that of $\mathrm{TiO}_{2}$, further demonstrating that $\mathrm{TiH}_{1.924}$ nanodots could be activated to generate large amounts of ROS under US irradiation.

To understand the mechanism of sono-sensitization effect of $\mathrm{TiH}_{1.924}$ nanodots, the optical absorbance spectra of solid $\mathrm{TiH}_{1.924}$ nanodots and the commercial $\mathrm{TiO}_{2}$ nanoparticles were measured (Fig. 3e). Based on the optical absorbance spectra and the kubelka-munk theory (Fig. 3f $)^{35,36}$, the optical bandgap of $\mathrm{TiO}_{2}$ was calculated to be $\sim 3.1 \mathrm{eV}$, which was consistent with the previous reports ${ }^{37-39}$. Interestingly, the bandgap of $\mathrm{TiH}_{1.924}$ nanodots was determined to be $\sim 2.7 \mathrm{eV}$, much lower than that of $\mathrm{TiO}_{2}$. The bandgap is related to the required minimum energy to realize electron excitation ${ }^{40,41}$. Thus, the lower bandgap means easier activation and would result in more ROS generation under external stimuli ${ }^{42,43}$. Based on the above discussion, the possible mechanism is proposed in Fig. 3g. Under the US irradiation, the valence electron receives energy and could transit from the valence band $(\mathrm{VB})$ to the conduction band $(\mathrm{CB})$, resulting in the generation of the electron-hole pairs and excess energy, which are captured by surrounding $\mathrm{O}_{2}$ and $\mathrm{H}_{2} \mathrm{O}$ molecules to generate ROS (e.g., $\left.{ }^{1} \mathrm{O}_{2}, \cdot \mathrm{O}_{2}^{-}, \cdot \mathrm{OH}\right)$. With a lower bandgap compared to that of $\mathrm{TiO}_{2}, \mathrm{TiH}_{1.924}$ nanodots thus could be easier to be activated to produce more ROS under US irradiation, useful for applications in SDT.

We then studied the optical properties of the obtained $\mathrm{TiH}_{1.924}$ nanodots. The as-made $\mathrm{TiH}_{1.924}$ nanodots showed black color and strong optical absorbance, which appeared to be independent to the wavelength and was extended to the second NIR (NIR-II) region (Fig. 3h), in which light would have much higher tissue-penetrating capability in comparison to that in the NIR-I window ${ }^{14,44}$. On this ground, we presented that $\mathrm{TiH}_{1.924}$ nanodots could use as a photothermal agent for effective NIR-II PTT $(1064 \mathrm{~nm})$. The extinction coefficient of $\mathrm{TiH}_{1.924}$ at $1064 \mathrm{~nm}$ was tested to be $\sim 10.27$ $\mathrm{L} \mathrm{g}^{-1} \mathrm{~cm}^{-1}$ (Supplementary Fig. 10), which was higher than that of black titania nanoparticles $\left(\mathrm{B}-\mathrm{TiO}_{2-x}, 5.54 \mathrm{~L} \mathrm{~g}^{-1} \mathrm{~cm}^{-1}\right)^{14}$, traditional graphene oxide $\left(\mathrm{GO}, 3.6 \mathrm{~L} \mathrm{~g}^{-1} \mathrm{~cm}^{-1}\right)^{45}$, and carbon nanodots (CQs, $\left.0.35 \mathrm{~L} \mathrm{~g}^{-1} \mathrm{~cm}^{-1}\right)^{46}$. Then, the photothermal performance of the $\mathrm{TiH}_{1.924}$ aqueous solution was further evaluated under 1064-nm NIR II laser. Significant concentration-dependent and laser-powerdependent photothermal heating effect was observed for these $\mathrm{TiH}_{1.924}$ nanodots (Fig. 3i, Supplementary Fig. 11). The photothermal conversion efficiency $(\eta)$ of $\mathrm{TiH}_{1.924}$ nanodots was calculated to be $\sim 58.6 \%$ (Fig. 3j, Supplementary Fig. 12), much higher than those of widely reported photothermal agents, like gold nanorods $(21 \%)^{47}$, copper selenide $\left(\mathrm{Cu}_{2-x} \mathrm{Se}\right)$ nanocrystals $(22 \%)^{48}$, copper sulfide $\left(\mathrm{Cu}_{9} \mathrm{~S}_{5}\right)$ nanocrystals $(25.7 \%)^{49}$, and prussian blue $(41.4 \%)^{50}$. In addition, there was almost no change of photothermal performance post five times ON/OFF laser cycles, showing the high photothermal stability of these $\mathrm{TiH}_{1.924}$ nanodots (Fig. 3k).

In order to increase their stabilities in the physiological environment, as-made $\mathrm{TiH}_{1.924}$ nanodots were modified with polyvinyl pyrrolidone (PVP), which could stabilize $\mathrm{TiH}_{1.924}$ nanodots likely via the chelating-coordination between the $\mathrm{O}$ atoms of PVP and Ti atoms of $\mathrm{TiH}_{1.924}$ (Supplementary Fig. 13) ${ }^{44,51}$. The amount of PVP coated on the surface of $\mathrm{TiH}_{1.924}$ nanodots was measured by thermogravimetric analysis (TGA) to be $\sim 26.4 \%$. Unlike as-made $\mathrm{TiH}_{1.924}$ nanodots which could be well dispersed in water but would aggregate in the presence of salt (e.g., in phosphatebuffered saline, PBS), $\mathrm{TiH}_{1.924}$-PVP nanodots showed great dispersity in both water, PBS, and cell culture medium for a week. Notably, the photothermal and sonodynamic performance of $\mathrm{TiH}_{1.924}$ nanodots did not change after surface modification with PVP or additional $\mathrm{H}_{2} \mathrm{O}_{2}$ treatments (Supplementary Figs. 14-16). 
a

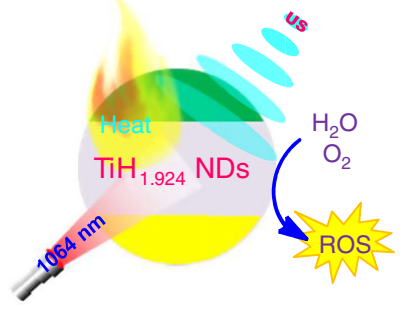

PTT \& SDT b
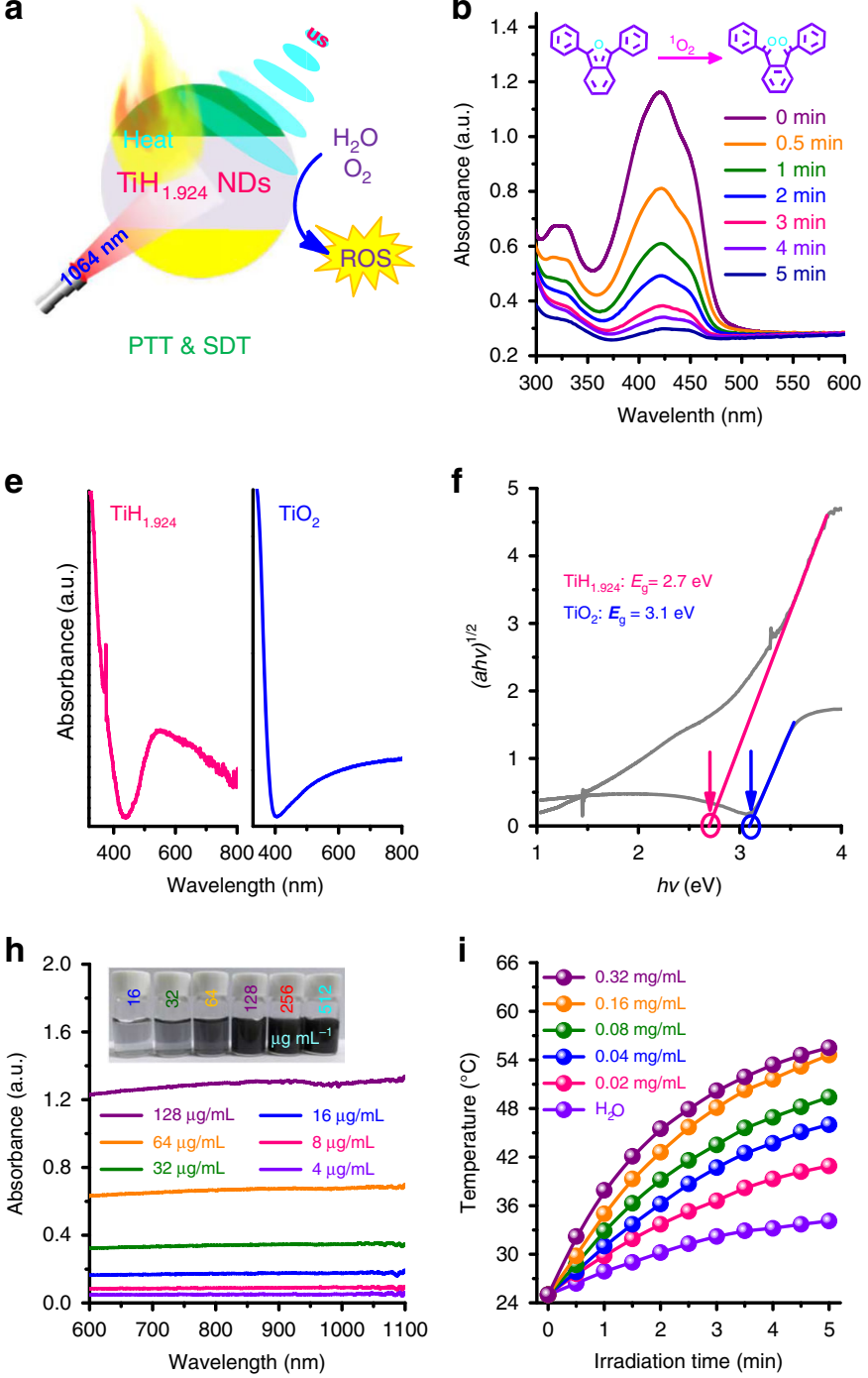

f

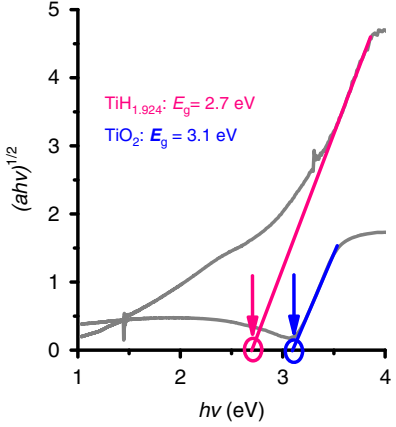

i

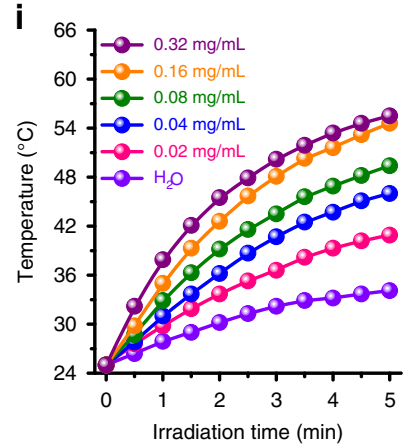

c

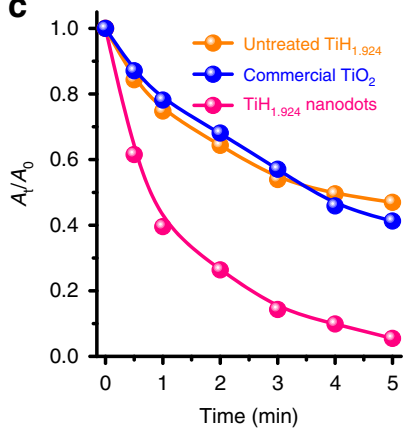

d

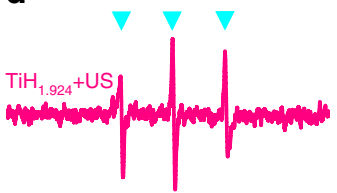

$\mathrm{TiO}_{2}+$ US

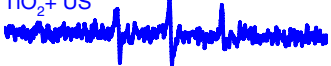

$\begin{array}{lllll}322 & 324 & 326 & 328 & 330\end{array}$

Magnetic field (mT)

g
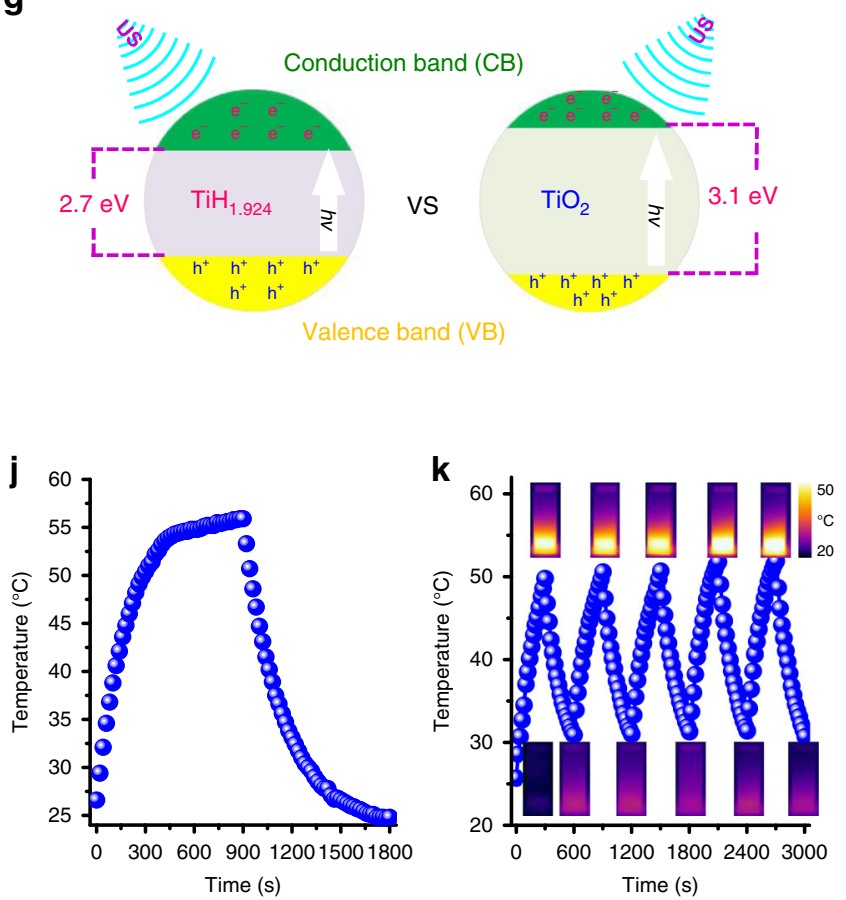

Fig. 3 Sonodynamic and photothermal performance of $\mathbf{T i H}_{\mathbf{1 . 9 2 4}}$ nanodots. a Schematic illustration of sonodynamic and photothermal properties of $\mathrm{TiH}_{1.924}$ nanodots. b Time-dependent oxidation of DPBF indicating ROS generation by US-activated $\mathrm{TiH}_{1.924}$ nanodots. c Comparison of DPBF oxidation by $\mathrm{TiH}_{1.924}$ nanodots, untreated $\mathrm{TiH}_{1.924}$, and commercial $\mathrm{TiO}_{2}$ under US irradiation for 5 min. d ESR spectra demonstrating $\mathrm{ROS}^{1}\left(\mathrm{O}_{2}\right)$ generation for TiH $\mathrm{H}_{1.924}$ and $\mathrm{TiO}_{2}$ under US irradiation for $1 \mathrm{~min}$. e, $\mathbf{f}$ Normalized absorption spectra (e) and optical bandgaps (f) of $\mathrm{TiH}_{1.924}$ nanodots and $\mathrm{TiO}_{2} . \mathbf{g} \mathrm{Schematic}$ illustration of the activation mechanism of $\mathrm{TiH}_{1.924}$ and $\mathrm{TiO}_{2}$ under US irradiation. $\mathbf{h}$ UV-vis-NIR absorbance spectra at different concentrations of $\mathrm{TiH}_{1.924}$ nanodots $\left(4,8,16,32,64\right.$, and $\left.128 \mu \mathrm{g} \mathrm{mL}^{-1}\right)$. The inset is the photograph of $\mathrm{TiH}_{1.924}$ nanodots with different concentrations. $\mathbf{i}$ Concentration-dependent photothermal heating curves of $\mathrm{TiH}_{1.924}$ nanodots $\left(0,0.02,0.04,0.08,0.16\right.$, and $\left.0.32 \mathrm{mg} \mathrm{mL}^{-1}\right)$. $\mathbf{j}$ The photothermal profile after laser exposure to reach a steady temperature and then to cool down by turning the laser off. $\mathbf{k}$ Heating/cooling profiles for five repeated ON-OFF cycles of laser irradiations.

In vitro mild PTT-enhanced SDT. With strong NIR-II absorbance and effective sono-sensitizing ability, we expected the utilization of $\mathrm{TiH}_{1.924}$-PVP for synergistic photothermalsonodynamic cancer therapy (Fig. 4a, Supplementary Fig. 17). Firstly, the standard methyl thiazolyl tetrazolium (MTT) assay demonstrated that $\mathrm{TiH}_{1.924}$-PVP nanodots show negligible cytotoxicity even at high concentrations $\left(400 \mu \mathrm{g} \mathrm{mL}^{-1}\right)$ toward $4 \mathrm{~T} 1$ tumor cells (Fig. 4b). Next, the in vitro PTT-enhanced SDT induced by $\mathrm{TiH}_{1.924}$-PVP was evaluated (Fig. 4c). After the mild PTT using the 1064-nm laser at the power density of $0.8 \mathrm{~W} \mathrm{~cm}-2$ for $10 \mathrm{~min}$, the cell culture temperature increased to $\sim 42{ }^{\circ} \mathrm{C}$ and the cell viability incubated with $\mathrm{TiH}_{1.924}$-PVP showed a slight decrease $(\sim 80.9 \%)$. When further US irradiation was conducted $\left(40 \mathrm{kHz}, 3 \mathrm{~W} \mathrm{~cm}^{-2}, 1 \mathrm{~min}\right.$ per cycle, 5 cycles), the $4 \mathrm{~T} 1$ cell viabilities significantly decreased to $\sim 10.6 \%$, presenting increased cell killing compared to $\mathrm{TiH}_{1.924}$-PVP treated cells exposed to US alone without pre-treatment by the NIR-II laser. In addition, the excellent cancer cell killing effect of mild PTT-enhanced SDT using $\mathrm{TiH}_{1.924}$-PVP was also confirmed by live/dead co-staining (live cells, calcein-AM, AM; dead cells, propidium iodide, PI) (Fig. 4d). This increased SDT performance may be ascribed to the mechanism that the laser treatment could change the cell membrane permeability and enhance the cell uptake of $\mathrm{TiH}_{1.924}-\mathrm{PVP}$ nanodots 52,53 .

Next, 2,7-dichlorofluorescein diacetate (DCFH-DA, green color) and dihydroethidium (DHE, red color) staining assays were also performed to determine intracellular ROS generation and verify the mechanism of $\mathrm{TiH}_{1.924}$-PVP as a sono-sensitizer to kill cancer cells under ultrasound (Fig. 4e, Supplementary Figs. 18 and 19) ${ }^{54}$. Cells in the control group, $\mathrm{TiH}_{1.924}$-PVP only group, laser only group, US only group, laser/US group, and $\mathrm{TiH}_{1.924} \mathrm{PVP} / \mathrm{NIR}$ group (mild PTT), all showed weak intracellular ROS-related 
a

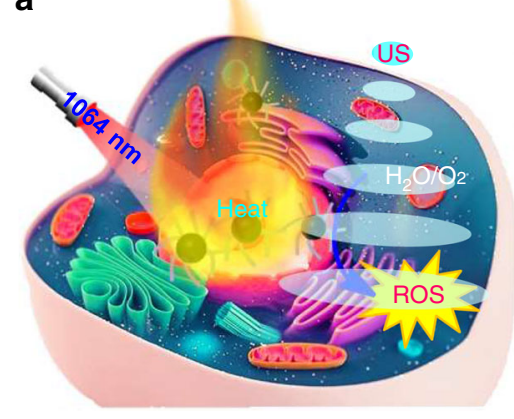

b

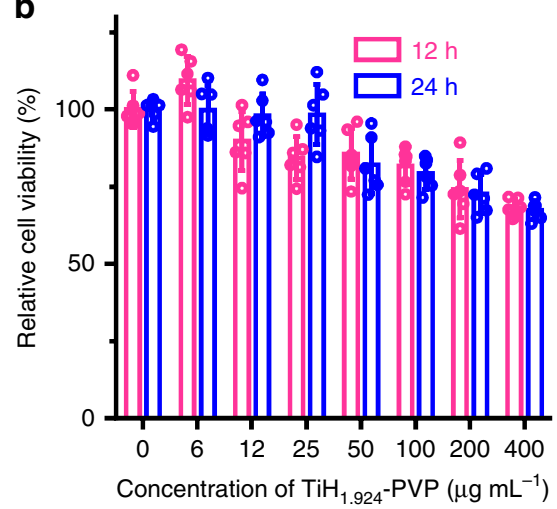

C

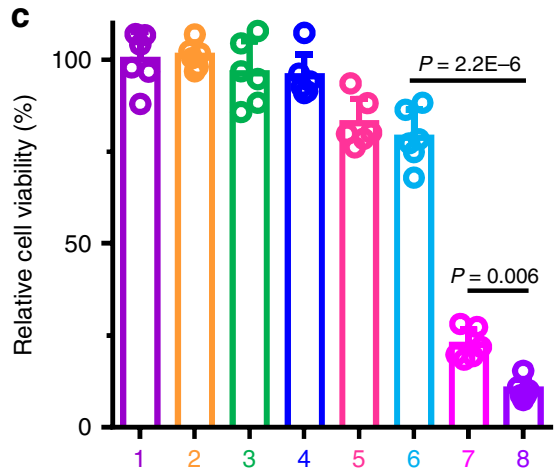

d AM/PI staining

Group 1

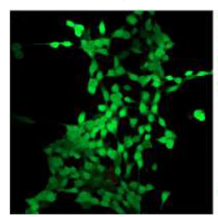

e

Group 1
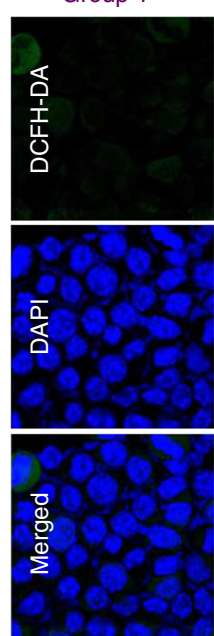

1: Control
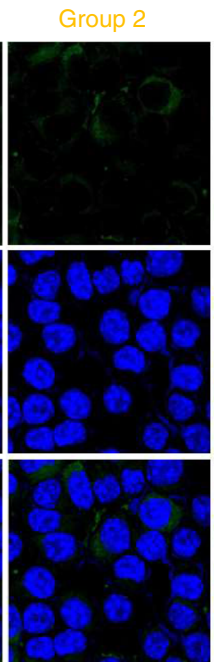

3: US

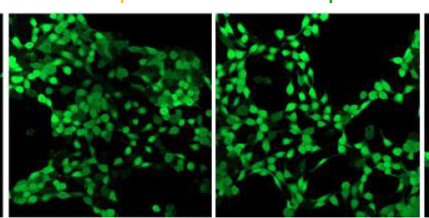

Group 4

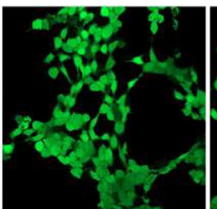

Group 5

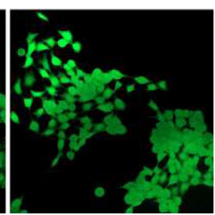

Group 6

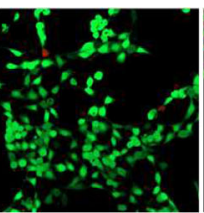

Group 7

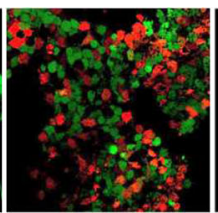

Group 8

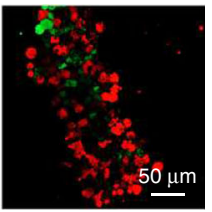

In vitro ROS staining

Group 3
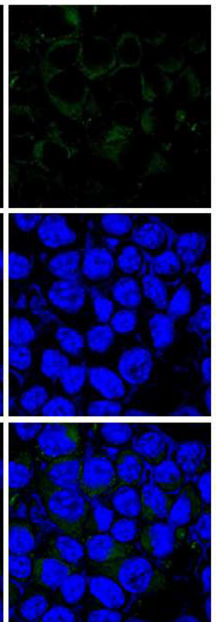

4: $\mathrm{TiH}_{1.924}-\mathrm{PVP}$
Group 4
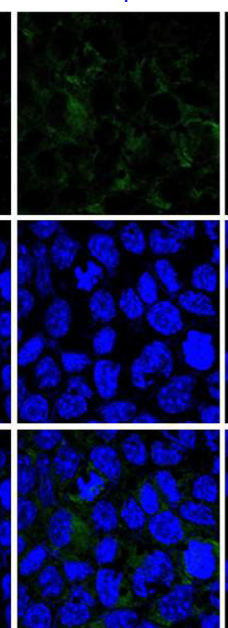

5: NIR/US
Group 5
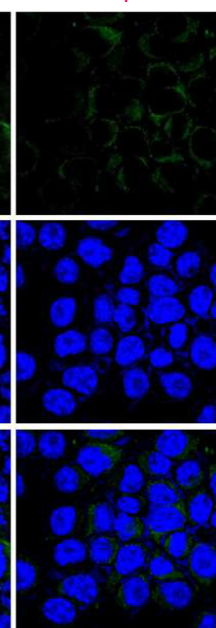

6: $\mathrm{TiH}_{1.924}$-PVP/NIR
Group 6

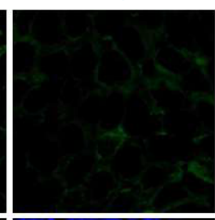

Group 7

Group 8
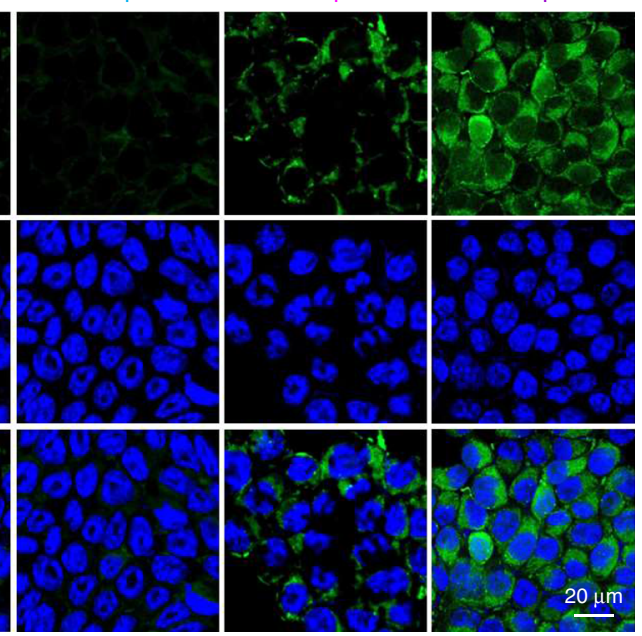

7: $\mathrm{TiH}_{1.924}$-PVP/US

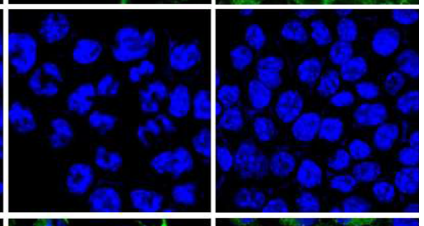

Fig. 4 In vitro mild PTT-enhanced SDT via TiH $\mathbf{T i n 2 4}_{\mathbf{1 . 9}}$-PVP. a Schematic illustration of $\mathrm{TiH}_{1.924}$-PVP for mild PTT-enhanced sonodynamic therapy. b Relative viabilities of $4 \mathrm{~T} 1$ cells after incubation with various concentrations of $\mathrm{TiH}_{1.924}$-PVP for $12 \mathrm{~h}$ and $24 \mathrm{~h}$ ( $n=6$ biologically independent samples). c Relative viabilities of $4 \mathrm{~T} 1$ cells after different treatments, including control, $\mathrm{TiH}_{1.924}-\mathrm{PVP}, \mathrm{NIR}, \mathrm{US}, \mathrm{NIR} / \mathrm{US}, \mathrm{TiH}_{1.924}-\mathrm{PVP} / \mathrm{NIR}, \mathrm{TiH}_{1.924}-\mathrm{PVP} / \mathrm{US}$, and TiH $\mathrm{H}_{1.924}-\mathrm{PVP} /$ NIR/US ( $n=6$ biologically independent samples). d Confocal images of $4 \mathrm{~T} 1$ cells stained with calcein AM (green, live cells) and propidium iodide (red, dead cells) after different treatments. e Confocal images of 4 T1 cells stained with DCFH-DA after various treatments. The nuclei and intracellular ROS were stained by DAPI (blue) and DCFH-DA (green), respectively. $\mathrm{TiH}_{1.924}-\mathrm{PVP}: 50 \mu \mathrm{g} \mathrm{mL}{ }^{-1}$, NIR laser: $1064 \mathrm{~nm}, 0.8 \mathrm{~W} \mathrm{~cm}{ }^{-2}, 10 \mathrm{~min} \mathrm{~T}<42^{\circ} \mathrm{C} ; \mathrm{US}$ irradiation: $40 \mathrm{kHz}, 3 \mathrm{~W} \mathrm{~cm}-2,1$ min per cycle, 5 cycles. Data are presented as mean values $\pm \mathrm{SD}$. Statistical significance was calculated with two-tailed Student's $t$ test $(\mathbf{c})$. A representative image of three biological replicates from each group is shown in $\mathbf{d}, \mathbf{e}$.

fluorescence. In contrast, strong fluorescent signals were clearly observed in cells from the $\mathrm{TiH}_{1.924}$-PVP/US and $\mathrm{TiH}_{1.924}$-PVP/ NIR/US groups, demonstrating the effective intracellular ROS generation by $\mathrm{TiH}_{1.924}$-PVP under US stimulation.

Mild PTT-defeated tumor hypoxia. After in vitro experiments, the in vivo behaviors of $\mathrm{TiH}_{1.924}$-PVP were studied using photoacoustic (PA) imaging and it could monitor the tumor uptake of NIR-absorbing $\mathrm{TiH}_{1.924}$-PVP nanodots. After intravenous (i.v.) injection of $\mathrm{TiH}_{1.924}$-PVP into 4T1-tumor-bearing balb/c mice for $8 \mathrm{~h}$, much obvious PA signals were clearly appeared in the tumor site (Fig. 5a, b), verified the tumor uptake of $\mathrm{TiH}_{1.924}$-PVP via the enhanced permeability and retention (EPR) effect. At the following time points, the PA signals 
a

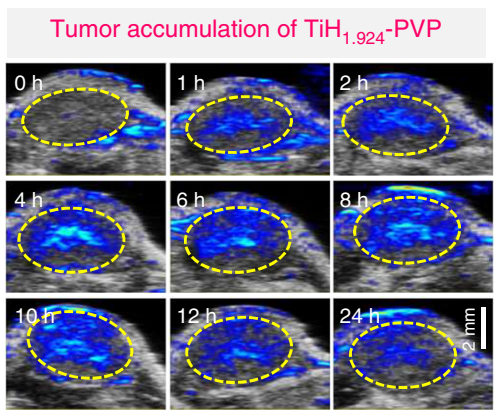

d

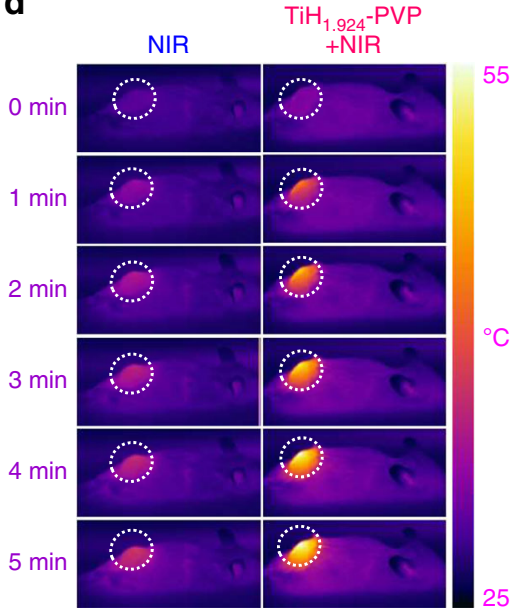

b

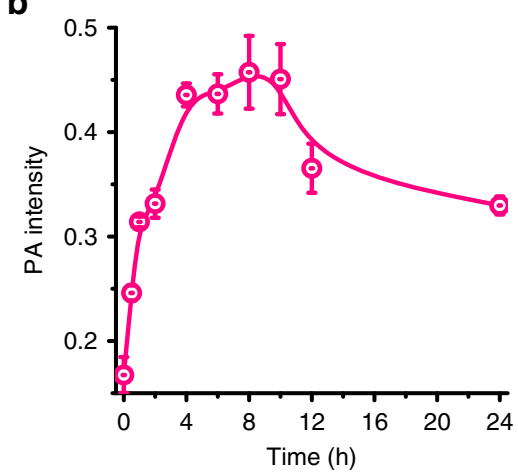

C

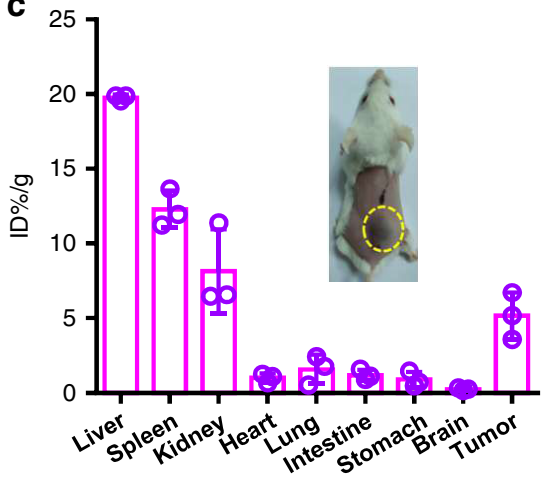

e

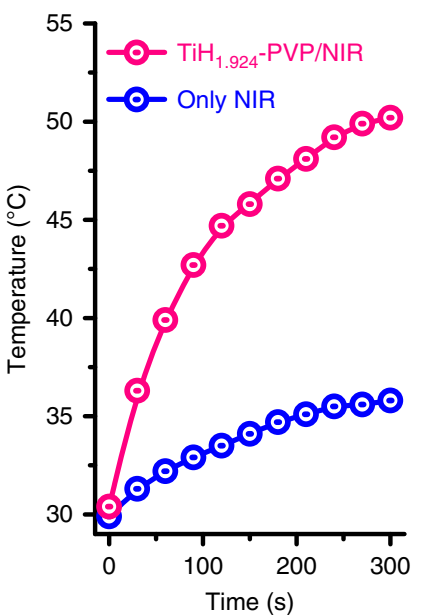

$\mathbf{f}$

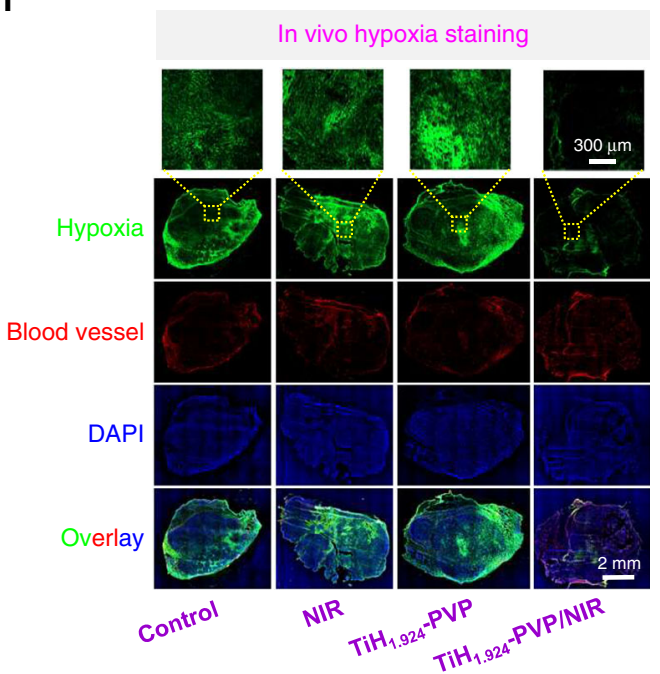

Fig. 5 In vivo tumor accumulation and mild PTT-defeated tumor hypoxia via $\mathbf{T i H}_{\mathbf{1 . 9 2 4}}$-PVP. a In vivo PA imaging of 4 T1 tumor-bearing mice after intravenously injected with $\mathrm{TiH}_{1.924}$-PVP. b Time-dependent tumor PA signals at $900 \mathrm{~nm}$ based on PA imaging data in a ( $n=3$ biologically independent mice). c Biodistribution of $\mathrm{TiH}_{1.924}-\mathrm{PVP}$ in mice ( $n=3$ biologically independent mice). d, e IR thermal images (d) and temperature change curves (e) of $4 \mathrm{~T} 1$ tumors under the 1064-nm laser irradiation, for untreated mice and $\mathrm{TiH}_{1.924}-\mathrm{PVP}$ injected mice (irradiated at $8 \mathrm{~h}$ p.i.). $\mathbf{f}$ Representative immunofluorescence images of tumor slices after hypoxia staining. The nuclei, blood vessels, and hypoxia areas were stained by DAPI (blue), anti-CD31 antibody (red), and antipimonidazole antibody (green), respectively. $\mathrm{TiH}_{1.924}$-PVP: $20 \mathrm{mg} \mathrm{kg}^{-1}$; NIR laser: $1064 \mathrm{~nm}, 0.8 \mathrm{~W} \mathrm{~cm}{ }^{-2}, 20 \mathrm{~min}$. A representative image of three biological replicates from each group is shown in $\mathbf{f}$. Data are presented as mean values \pm SD.

gradually decrease, likely due to the clearance of the ultrasmall $\mathrm{TiH}_{1.924}$-PVP from the tumor. In addition, the biodistribution of nanodots in the tumor was then quantitatively studied by measuring the content of titanium ions through inductively coupled plasma optical emission spectrometry (ICP-OES) at $8 \mathrm{~h}$ post injection (p.i.). The tumor uptake of $\mathrm{TiH}_{1.924}$-PVP was determined to be $\sim 5.2 \% \mathrm{ID} \mathrm{g}^{-1}$, further confirming the efficient tumor accumulation of these nanodots (Fig. $5 \mathrm{c}$ ).

Afterward, the in vivo photothermal performance of $\mathrm{TiH}_{1.924^{-}}$ PVP for NIR II-induced hyperthermia was investigated own to the strong NIR absorbance and high tumor accumulation of $\mathrm{TiH}_{1.924}$-PVP nanodots. And the surface temperature of tumors was recorded by infrared (IR) thermal imaging. 4T1 tumorsbearing mice post i.v. injection of $\mathrm{TiH}_{1.924}$ - PVP for $8 \mathrm{~h}$ were exposed to the $1064-\mathrm{nm}$ laser irradiation $\left(0.8 \mathrm{~W} \mathrm{~cm}^{-2}, 5 \mathrm{~min}\right)$ (Fig. 5d, e). Obviously, the tumor temperatures for $\mathrm{TiH}_{1.924}-\mathrm{PVP}$ treated mice quickly increased to $50^{\circ} \mathrm{C}$, while that of the control group showed much less significant temperature increase.

Due to aberrant cancer cell proliferation and distorted blood tumor vessels, hypoxia arises in a wide variety of solid tumors and often causes the failure of cancer therapies, especially for those that consume oxygen in the cell killing process such as radiotherapy, photodynamic therapy (PDT), and SDT ${ }^{55-57}$. Based on previous reports, the mild photothermal effect may increase intra-tumoral blood flow and then overcome tumor hypoxia ${ }^{58-60}$. To confirm this effect, immune-fluorescence hypoxia staining assay was conducted (Fig. 5f). Obviously, $\mathrm{TiH}_{1.924}$-PVP plus NIR-II irradiation group showed a significantly decrease of the hypoxia signals, suggesting that the mild photothermal effect could efficiently overcome the tumor hypoxia, favorable for defeating hypoxia-associated SDT resistance.

In vivo mild PTT-enhanced SDT. Then, we conducted the mild PTT-enhanced SDT on 4T1 tumor-bearing mice using $\mathrm{TiH}_{1.924^{-}}$ PVP. All of the mice were divided into five groups: (1) Control; (2) $\mathrm{TiH}_{1.924}$-PVP (i.v. injection, $20 \mathrm{mg} \mathrm{kg}^{-1}$ ); (3) NIR (1064 nm, $\left.0.8 \mathrm{~W} \mathrm{~cm}^{-2}, 20 \mathrm{~min}, \mathrm{~T}<45^{\circ} \mathrm{C}\right)+\mathrm{US}\left(40 \mathrm{kHz}, 3 \mathrm{~W} \mathrm{~cm}^{-2}, 1 \mathrm{~min}\right.$ per cycle, 20 cycles); (4) $\mathrm{TiH}_{1.924^{-}} \mathrm{PVP}+\mathrm{NIR}$; (5) $\mathrm{TiH}_{1.924^{-}}$ PVP + US; (6) $\mathrm{TiH}_{1.924}$-PVP + NIR + US. At $8 \mathrm{~h}$ post i.v. injection of $\mathrm{TiH}_{1.924}$-PVP, the tumors were treated with $1064 \mathrm{~nm}$ laser and subsequent US irradiation (Fig. 6a). After various treatments, the tumor growth on different groups of mice was monitored. Compared with control, $\mathrm{TiH}_{1.924}$-PVP injection alone, or NIR/US treated for saline injected mice showed no appreciable effect to the tumor group (Fig. 6b, c, Supplementary Fig. 20A). The mild PTT with $\mathrm{TiH}_{1.924}$-PVP could only partially inhibit the tumor 
a
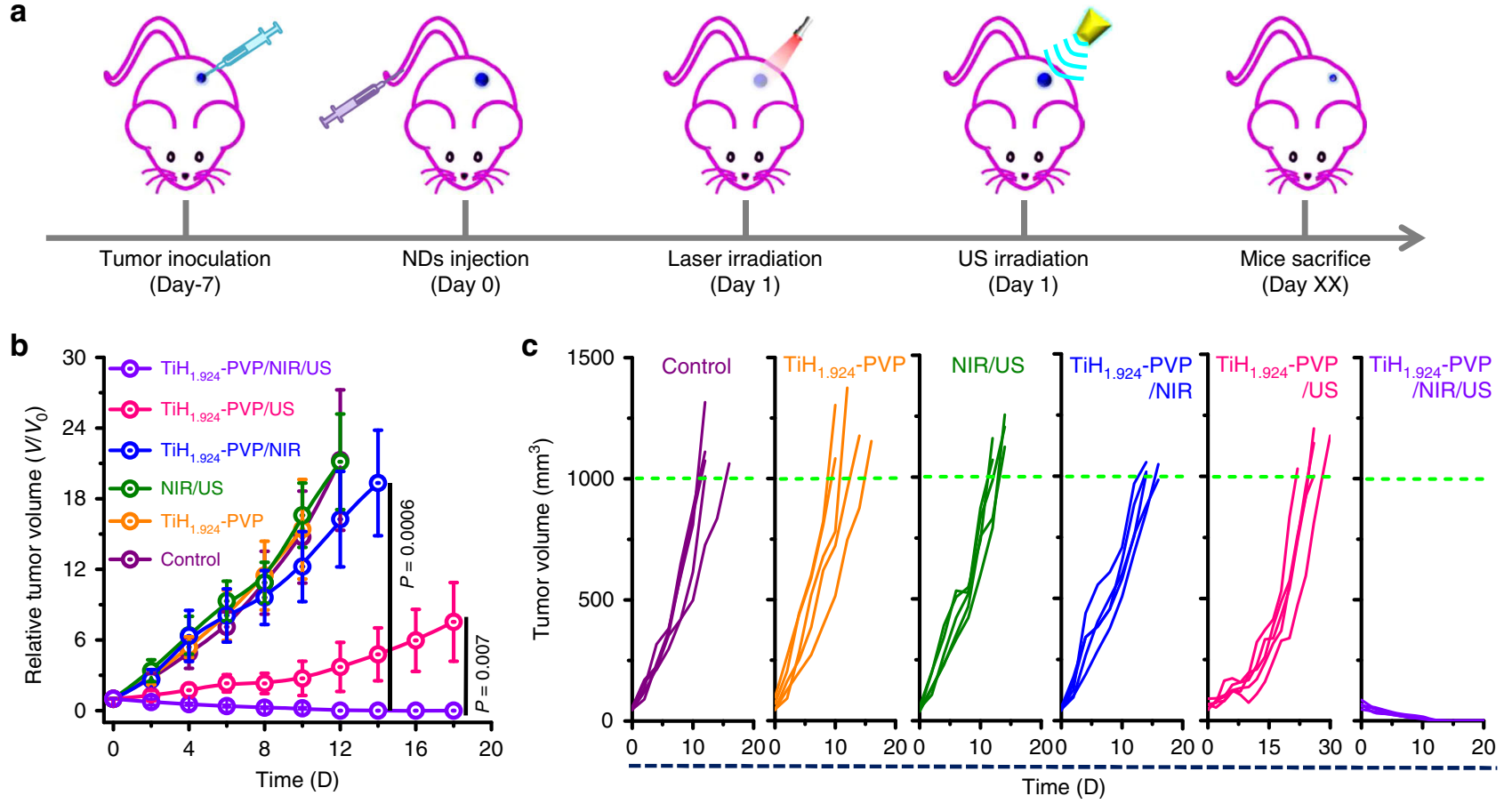

d
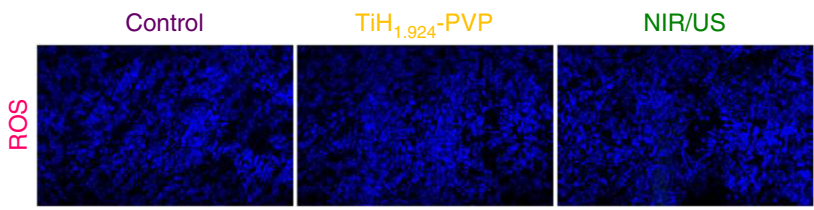

$\mathrm{TiH}_{1.924}$-PVP/NIR

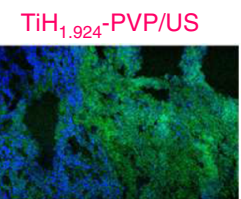

$\mathrm{TiH}_{1.924}-\mathrm{PVP} / \mathrm{NIR} / \mathrm{US}$
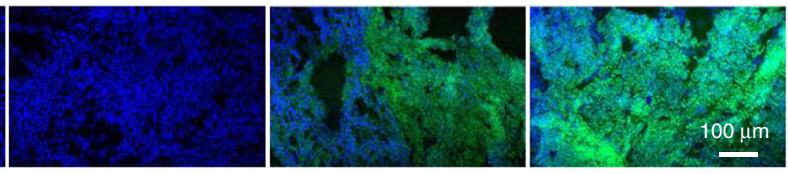

e
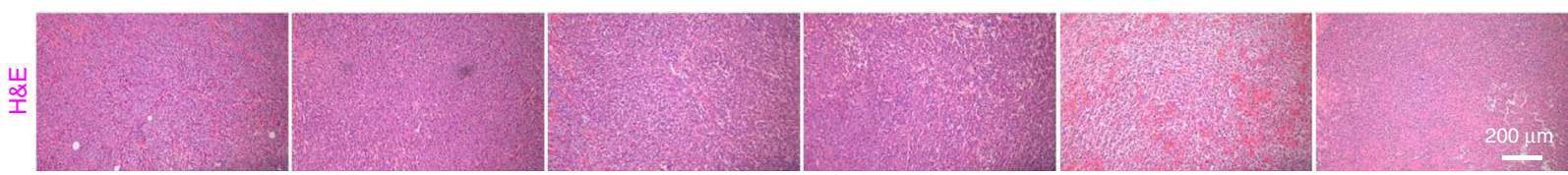

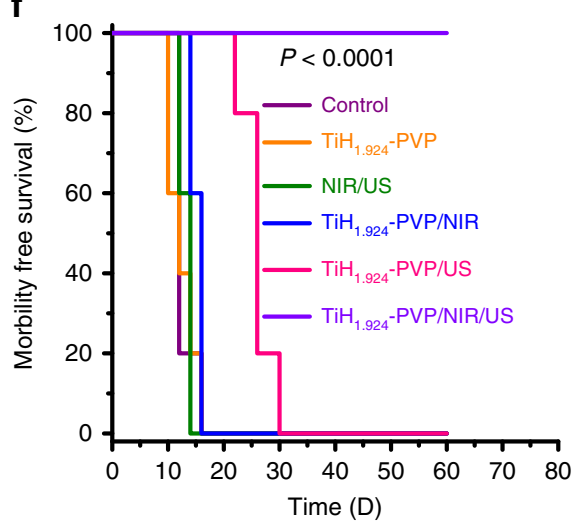

g

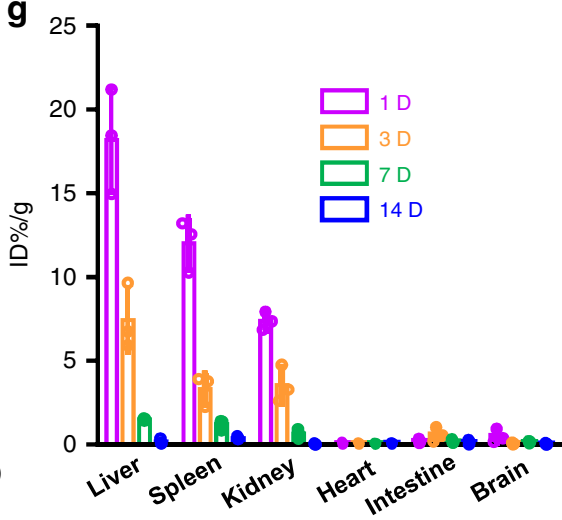

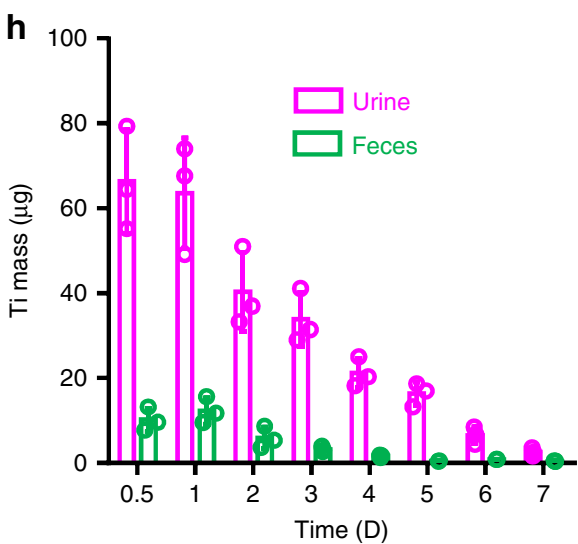

Fig. 6 In vivo mild PTT-enhanced SDT via TiH $\mathbf{1 . 9 2 4}_{\mathbf{1}}$-PVP. a Schematic illustration to show the combination of PTT and SDT with TiH ${ }_{1.924}-\mathrm{PVP}$ nanodots.

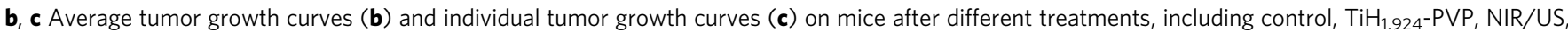
$\mathrm{TiH}_{1.924}$-PVP/NIR, $\mathrm{TiH}_{1.924}$-PVP/US, and $\mathrm{TiH}_{1.924}$-PVP/NIR/US ( $n=5$ biologically independent mice). d Micrograph of DCFH-DA stained tumor slices collected for mice receiving different treatments. e H\&E stained tumor slices collected from different treatment groups. $\mathbf{f}$ Survival curves of mice after various treatments. $\mathbf{g}$ Biodistribution of $\mathrm{TiH}_{1.924}$-PVP post i.v. injection in mice on different days $(n=3$ biologically independent mice). $\mathbf{h}$ The detected Ti mass in urine and feces at different time points post i.v. injection of $\mathrm{TiH}_{1.924}$-PVP ( $n=3$ biologically independent mice). The Ti contents were measured by ICP-OES. TiH 1.924 -PVP: $20 \mathrm{mg} \mathrm{kg}^{-1}$; NIR laser: $1064 \mathrm{~nm}, 0.8 \mathrm{~W} \mathrm{~cm}^{-2}, 20 \mathrm{~min}, T<45^{\circ} \mathrm{C}$; US irradiation: $40 \mathrm{kHz}, 3 \mathrm{~W} \mathrm{~cm}^{-2}, 1 \mathrm{~min}$ per cycle, $20 \mathrm{cycles}$. A representative image of three biological replicates from each group is shown in $\mathbf{d}$, e. Data are presented as mean values \pm SD. Statistical significance was calculated with two-tailed Student's $t$ test (b) and Logrank test (two-sided) for trend (f). 
growth. The tumor growth of the SDT group $\left(\mathrm{TiH}_{1.924} \mathrm{PVP} / \mathrm{US}\right)$ was remarkably suppressed, suggesting the excellent SDT performance of $\mathrm{TiH}_{1.924}$-PVP. Interestingly, the $\mathrm{TiH}_{1.924}-\mathrm{PVP} / \mathrm{NIR} /$ US group showed the most remarkable therapeutic outcome, and the tumor tissues were completely eradiated without recurrence during two months. The survival time of mice in the SDT group $\left(\mathrm{TiH}_{1.924}\right.$-PVP/US) was prolonged compared to the other four groups (control, $\mathrm{TiH}_{1.924} \mathrm{PVP}, \mathrm{NIR} / \mathrm{US}$, and mild PTT group) (Fig. 6f). More importantly, the mice in the mild PTT-enhanced SDT group showed $100 \%$ survival for two months, further demonstrating an obvious synergistic therapeutic outcome for the combined PTT-SDT with $\mathrm{TiH}_{1.924}$-PVP in comparison to the single-modality SDT or mild PTT.

To further understand the mechanism of synergistic therapy, ROS staining of tumor slices was conducted to evaluate the ROS levels in the tumor post different treatments (Fig. 6d). Compared with the weak green fluorescence in tumor slices from control, $\mathrm{TiH}_{1.924}$-PVP, NIR/US, and $\mathrm{TiH}_{1.924}$-PVP/NIR groups, the $\mathrm{TiH}_{1.924} \mathrm{PVP} / \mathrm{US}$ group showed obvious green fluorescence, and the strongest ROS-related fluorescence was observed in the combined laser plus US treatment group $\left(\mathrm{TiH}_{1924} \mathrm{PVP} / \mathrm{NIR} /\right.$ US). Our results indicated the mild PTT could overcome tumor hypoxia and facilitate the SDT-triggered ROS production. In addition, hematoxylin and eosin $(\mathrm{H} \& \mathrm{E})$ staining were conducted at $24 \mathrm{~h}$ after different treatments. Tumor cells were severely damaged in the SDT group and mild PTT-enhanced SDT group, while the other four groups showed little cell dead (Fig. 6e). These results confirmed the efficient synergistic effects induced by mild PTTenhanced SDT, in the presence of $\mathrm{TiH}_{1.924}-\mathrm{PVP}$ as a concurrent sono-sensitizer and photothermal nanoagent.

The body clearance behaviors. In two weeks after the treatment, the body weights of mice showed no significant change, indicating no apparent acute toxicity of $\mathrm{TiH}_{1.924}$-PVP (Supplementary Fig. 20B). Next, we further investigated the body clearance behaviors of $\mathrm{TiH}_{1.924}$ - $\mathrm{PVP}$ after systemic injection, and a timedependent biodistribution study was conducted after i.v. injection of $\mathrm{TiH}_{1.924}$-PVP nanodots (Fig. $6 \mathrm{~g}$ ). Relatively high retention of $\mathrm{TiH}_{1.924}$-PVP was observed in the liver $\left(18.2 \pm 3.1 \% \mathrm{ID} \mathrm{g}^{-1}\right)$, spleen $\left(12.1 \pm 1.5 \% \mathrm{ID} \mathrm{g}^{-1}\right)$, and kidney $\left(7.4 \pm 0.5 \% \mathrm{ID} \mathrm{g}^{-1}\right)$ at $24 \mathrm{~h}$ p.i. Importantly, rapid decrease of Ti levels in these organs was observed over time, indicating the efficient clearance of $\mathrm{TiH}_{1.924^{-}}$ PVP. After 14 days, the Ti retention in major organs drastically decreased to be $<0.5 \% \mathrm{ID} \mathrm{g}^{-1}$, indicating the nearly complete clearance of $\mathrm{TiH}_{1.924}-\mathrm{PVP}$. To further investigate the clearance pathway, the Ti concentrations in the urine and feces were also measured. High levels of Ti were observed in the urine, strongly evidencing the elimination of $\mathrm{TiH}_{1.924}$-PVP nanodots via the renal filtration pathway (Fig. 6h). In addition, H\&E staining of the major organs (heart, liver, spleen, kidney, heart, lung, and brain) also confirmed the negligible toxicity of $\mathrm{TiH}_{1.924} \mathrm{PVP}$ to mice at this therapeutic dose (Supplementary Fig. 21). With efficient clearance and no acute toxicity, such $\mathrm{TiH}_{1.924}$-PVP nanodots could be safe for in vivo use without long-term toxicity within the appropriate dose range.

\section{Discussion}

In summary, nano-structured $\mathrm{TiH}_{1.924}$ materials were synthesized via the liquid-phase exfoliation method. It was found that when the surface energy of the applied solvent had a good match with that of the $\mathrm{TiH}_{1.924}$ powder, efficient exfoliation of such metal hydride powder into nanoparticles could be realized. Using the same method, a series of metal hydrides powders $\left(\mathrm{TiH}_{1.924}, \mathrm{ZrH}_{2}\right.$, $\mathrm{CaH}_{2}$, and $\mathrm{HfH}_{1.983}$ ) were successfully exfoliated into small nanoparticles. With strong NIR-II absorbance and efficient
US-triggered ROS production ability, $\mathrm{TiH}_{1.924}$ nanodots with PVP modification were further applied for the combined PTTSDT therapy with great in vivo tumor destruction efficacy. Such $\mathrm{TiH}_{1.924}$ nanodots present the following advantages as therapeutic nano-agent. (1) These $\mathrm{TiH}_{1.924}$-PVP nanodots exhibit excellent sonodynamic performance in US-triggered ROS generation due to the reduced band-gap in $\mathrm{TiH}_{1.924}$ compared to that of $\mathrm{TiO}_{2}$. (2) The strong NIR absorption of $\mathrm{TiH}_{1.924}$-PVP could enable enhanced photothermal-sonodynamic therapy, in which the mild hyperthermia-induced tumor hypoxia relief would lead to improved sonodynamic tumor killing. (3) Containing biocompatible elements ( $\mathrm{Ti}$ and $\mathrm{H}$ ), $\mathrm{TiH}_{1.924}$-PVP nanodots with ultra-small sizes could allow their efficient body excretion without appreciable toxicity. Moreover, this work illustrates the promises of nano-structured metal hydrides nanomedicine platform against cancer and possibly other types of diseases.

\section{Methods}

Materials. Titanium hydride $\left(\mathrm{TiH}_{1.924}\right)$, zirconium hydride $\left(\mathrm{ZrH}_{2}\right)$, calcium hydride $\left(\mathrm{CaH}_{2}\right)$, hafnium hydride $\left(\mathrm{HfH}_{1.983}\right)$, and $\mathrm{N}$-methyl pyrrolidone (NMP) were purchased from Aladdin reagent Co., Ltd. (Shanghai, China). 1,3-diphenylisobenzofuran (DPBF), Polyvinyl pyrrolidone (PVP, MW $10 \mathrm{k}$ ), 2,2,6,6-tetramethylpiperidine (TEMP), and 5,5-dimethyl-pyrroline- $N$-oxide (DMPO) were obtained from SigmaAldrich. All chemicals were of analytical grade and used without further purification.

Synthesis of $\mathbf{T i H}_{\mathbf{1 . 9 2 4}}$ nanodots. $100 \mathrm{mg}$ commercial $\mathrm{TiH}_{1.924}$ powder was dispersed in $20 \mathrm{~mL}$ NMP. The mixture was treated under ultrasonication for different periods of time (Ultrasonic Cleaner, KQ-100KDB, power: $\sim 100 \mathrm{~W}$, temperature: $\left.\sim 15^{\circ} \mathrm{C}\right)$. After ultrasonic treatment for $20 \mathrm{~min}, \mathrm{TiH}_{1.924}$ nanodots were obtained and further purified by centrifugation $(64 \mathrm{k} \times g, 10 \mathrm{~min})$ and washing repeatedly with anhydrous ethanol. Via the same method, zirconium hydride $\left(\mathrm{ZrH}_{2}\right)$ nanodots, calcium hydride $\left(\mathrm{CaH}_{2}\right)$ nanodots, and hafnium hydride $\left(\mathrm{HfH}_{1.983}\right)$ nanoparticles were also synthesized.

Modification of $\mathbf{T i H}_{\mathbf{1 . 9 2 4}}$ nanodots. The as-synthesized $\mathrm{TiH}_{1.924}$ nanodots were modified by polyvinylpyrrolidone (PVP) ${ }^{44,51}$. Briefly, $20 \mathrm{mg} \mathrm{TiH}{ }_{1.924}$ and $200 \mathrm{mg}$ PVP (MW $10 \mathrm{k}$ ) were dissolved in $50 \mathrm{~mL}$ anhydrous ethanol and refluxed at $50^{\circ} \mathrm{C}$ for $8 \mathrm{~h}$. After collecting by centrifugation $(64 \mathrm{k} \times g, 10 \mathrm{~min})$ and washing with water and ethanol, the final $\mathrm{TiH}_{1.924}$-PVP nanodots were dispersed in deionized water, and stored at $4{ }^{\circ} \mathrm{C}$ for further use (concentration, $2 \mathrm{mg} \mathrm{mL}^{-1}$ ).

Characterization. Transmission electron microscope (TEM) imaging and elemental mapping were carried out by FEI Tecnai F20 TEM. Powder X-ray diffraction (XRD) measurement was conducted by a PANalytical X-ray diffractometer equipped with $\mathrm{CuKa}$ radiation $(\lambda=0.15406 \mathrm{~nm})$. XPS analysis was performed by the PHI Quantera SXM X-ray photoelectron spectrometer with an Al Ka monochromator source. ROS was quantified by an ESR spectrometer (Bruker EMXplus). UV-vis-NIR absorbance spectra were recorded by PerkinElmer Lambda 750 UVvis-NIR spectrophotometer. The ultrasonic generator was made by Hainertec (Suzhou) Co., Ltd. The absolute Ti contents were determined by ICP-OES (inductively coupled plasma optical emission spectrometry).

Quantitative analysis of the generation of ROS. $1 \mathrm{~mL} \mathrm{TiH}_{1.924}\left(20 \mu \mathrm{g} \mathrm{mL}^{-1}\right)$ was mixed with $20 \mu \mathrm{L}$ DPBF $\left(1 \mathrm{mg} \mathrm{mL}^{-1}\right)$. After different US $\left(40 \mathrm{kHz}, 3 \mathrm{~W} \mathrm{~cm}^{-2}\right)$ durations, the absorbance changes of DPBF at $420 \mathrm{~nm}$ were recorded to quantify the generation of ROS by US-activated $\mathrm{TiH}_{1.924}$. ESR technology combined with TEMP (for ${ }^{1} \mathrm{O}_{2}$ detection) or DMPO (for $\cdot \mathrm{OH}$ detection) was employed to detect different types of the generated ROS. In this case, $1 \mathrm{~mL} \mathrm{TiH}_{1.924}\left(20 \mu \mathrm{g} \mathrm{mL}^{-1}\right)$ was mixed with $20 \mu \mathrm{L}$ TEMP $(1 \mathrm{M})$ or $10 \mu \mathrm{L}$ DMPO $(1 \mathrm{M})$ and exposed to US irradiation $\left(40 \mathrm{kHz}, 3 \mathrm{~W} \mathrm{~cm}^{-2}\right)$ for $1 \mathrm{~min}$. The characteristic peak signals were detected by the ESR spectrometer. The settings for the EPR spectrometer were as follows: center field, $3520 \mathrm{G}$; sweep width, $100 \mathrm{G}$; microwave frequency, $9.77 \mathrm{GHz}$; modulation frequency, $100 \mathrm{kHz}$; power, $20.00 \mathrm{~mW}$.

Photothermal performance of $\mathbf{T i H}_{\mathbf{1 . 9 2 4}}$ nanodots. The photothermal performance of $\mathrm{TiH}_{1.924}$ was analyzed by irradiating a glass cuvette containing a dispersion of $\mathrm{TiH}_{1.924}$ nanodots. The extinction coefficient and the photothermal conversion efficiency were calculated according to the previous studies ${ }^{44}$.

Cellular experiments. Murine breast cancer $4 \mathrm{~T} 1$ cells were cultured in the standard cell culture medium at $37^{\circ} \mathrm{C}$ under $5 \% \mathrm{CO}_{2}$. For the in vitro cytotoxicity test, $4 \mathrm{~T} 1$ cells seeded in 96-well plates were incubated with different concentrations $\left(0-400 \mu \mathrm{g} \mathrm{mL}^{-1}\right)$ of $\mathrm{TiH}_{1.924}$-PVP for $12 \mathrm{~h}$ and $24 \mathrm{~h}$. Relative cell viabilities were tested by the standard MTT assay. 
For in vitro mild PTT-enhanced SDT, $4 \mathrm{~T} 1$ cells were incubated with $\mathrm{TiH}_{1.924^{-}}$ PVP $\left(50 \mu \mathrm{g} \cdot \mathrm{mL}^{-1}\right)$ for $8 \mathrm{~h}$, followed by laser irradiation $\left(1064 \mathrm{~nm}, 0.8 \mathrm{~W} \mathrm{~cm}{ }^{-2}, 10\right.$ min, $\left.T<42^{\circ} \mathrm{C}\right)$ or US irradiation $\left(40 \mathrm{kHz}, 3 \mathrm{~W} \mathrm{~cm}^{-2}, 1\right.$ min per cycle, 5 cycles). The cell viabilities were determined afterward by the MTT assay.

For live/dead staining, 4T1 cells under different treatments (including control, $\mathrm{TiH}_{1.924}$-PVP, NIR, US, NIR/US, $\mathrm{TiH}_{1.924}-\mathrm{PVP} / \mathrm{NIR}, \mathrm{TiH}_{1.924}$-PVP/US and $\mathrm{TiH}_{1.924}$-PVP/NIR/US) were stained with calcein AM (AM, live cell) and propidium iodide (PI, dead cell). For ROS detection, the treated $4 \mathrm{~T} 1$ cells were stained with DCFH-DA $(20 \mu \mathrm{M})$ for $30 \mathrm{~min}$. All the images were acquired by a confocal laser scanning microscope (CLSM, Zeiss Axio-Imager LSM-800).

Tumor model. Balb/c mice were purchased from Nanjing Sikerui Biological Technology Co. Ltd, and all animal experiments were carried out under the permission by Soochow University Laboratory Animal Center. Six-week-old male $\mathrm{Balb} / \mathrm{c}$ mice $(18 \pm 2 \mathrm{~g})$ were used as the animal model in this work. Mice were housed in groups of 5 mice per individually ventilated cage in a 12-h light-dark cycle (8:00-20:00 light; 20:00-8:00 dark), with constant room temperature $\left(21 \pm 1^{\circ} \mathrm{C}\right)$ and relative humidity (40-70\%). All mice had access to food and water ad libitum.

Hypoxia tumor analysis. For immunohistochemistry analysis, $4 \mathrm{~T} 1$ tumor-bearing mice were intravenously injected with $\mathrm{TiH}_{1.924}-\mathrm{PVP}\left(20 \mathrm{mg} \cdot \mathrm{kg}^{-1}\right)$. At $8 \mathrm{~h}$ p.i., tumors on these mice were exposed to the 1064-nm laser irradiation for $20 \mathrm{~min}$ with their temperature maintained at $\sim 45^{\circ} \mathrm{C}$. Then immediately, tumors were surgically excised for hypoxia staining assay using the Hypoxyprobe-1 plus kit (Hypoxyprobe Inc) following the standard protocol ${ }^{61,62}$. Anti-pimonidazole mouse monoclonal antibody conjugated with FITC (FITC-Mab1, Hypoxyprobe Inc.; Cat. No.: HP2-100Kit; Lot No.: 04-11-19; Clone: 4.3.11.3; Dilution: 1:200) and Alex 488conjugated goat anti-mouse secondary antibody (Jackon Inc., Cat. No.: 115-545003, Lot No.: 146108, RRID: AB_2338840; dilution: 1:200) for hypoxia staining. Rat anti-CD31 mouse monoclonal antibody (Biolegend Inc., Cat. No.: 102402, Lot No.: B226360, Clone: 390; dilution: 1:100) and Rhodamine-conjugated donkey anti-rat secondary antibody (Jackon Inc. Cat. No.: 712-025-150, Lot No.: 147079, RRID: AB_2340635; Dilution: 1:200) for blood vessel staining.

In vivo mild PTT enhanced SDT. Mice bearing $4 \mathrm{~T} 1$ tumors $\left(\sim 100 \mathrm{~cm}^{3}\right)$ were divided into six groups ( $n=5$ per group): (1) control; (2) $\mathrm{TiH}_{1.924} \mathrm{PVP}$ (i.v. injection, $\left.20 \mathrm{mg} \mathrm{kg}^{-1}\right)$; (3) NIR ( $\left.1064 \mathrm{~nm}, 0.8 \mathrm{~W} \mathrm{~cm}^{-2}, 20 \mathrm{~min}, T<45^{\circ} \mathrm{C}\right)+\mathrm{US}(40 \mathrm{kHz}$, $3 \mathrm{~W} \mathrm{~cm}^{-2}, 1$ min per cycle, 20 cycles); (4) $\mathrm{TiH}_{1.924}$-PVP (i.v. injection, $20 \mathrm{mg} \mathrm{kg}^{-1}$ ) + NIR $\left(1064 \mathrm{~nm}, 0.8 \mathrm{~W} \mathrm{~cm}^{-2}, 20 \mathrm{~min}, T<45^{\circ} \mathrm{C}\right.$ ); (5) $\mathrm{TiH}_{1.924}$-PVP (i.v. injection, $20 \mathrm{mg} \mathrm{kg}^{-1}$ ) + US ( $40 \mathrm{kHz}, 3 \mathrm{~W} \mathrm{~cm}^{-2}, 1$ min per cycle, 20 cycles); (6) $\mathrm{TiH}_{1.924}-\mathrm{PVP}$ (i.v. injection, $\left.20 \mathrm{mg} \mathrm{kg}^{-1}\right)+\mathrm{NIR}\left(1064 \mathrm{~nm}, 0.8 \mathrm{~W} \mathrm{~cm}^{-2}, 20 \mathrm{~min}, T<45^{\circ} \mathrm{C}\right)+\mathrm{US}$ $\left(40 \mathrm{kHz}, 3 \mathrm{~W} \mathrm{~cm}{ }^{-2}, 1 \mathrm{~min}\right.$ per cycle, 20 cycles). At $8 \mathrm{~h}$ after i.v. injection, the tumors were treated with laser irradiation, or US irradiation, or laser irradiation + US exposure, sequentially. Tumor temperature and thermal images were monitored and recorded by an IR thermal camera (Infrared Cameras. Inc). Tumor sizes and body weight were monitored every two days. The tumor volumes were calculated by the formula: volume $=$ length $\times$ width $^{2} / 2$. For in vivo H\&E staining, tumors in different groups were collected on the second day post treatment.

In vivo metabolism study. Healthy mice after i.v. injection with $\mathrm{TiH}_{1.924}-\mathrm{PVP}(20$ $\mathrm{mg} \cdot \mathrm{kg}^{-1}$ ) was sacrificed at $1,3,7$, and 14 days, respectively. The major organs were collected, with one halves used for H\&E staining, and the other halves used for detection of Ti levels by ICP-OES after these organs were solubilized by aqua regia. To study the excretion pathway, mice after i.v. injection with $\mathrm{TiH}_{1.924}-\mathrm{PVP}$ nanodots were kept in metabolic cages to collect their feces and urine at various time points, which were solubilized by aqua regia measured by ICP-OES to determine Ti levels.

Software. All statistical analyses were performed on Origin 8.5, Excel 2010 and GraphPad Prism 6. Fluorescent images were collected by Confocal Microscopy (Zeiss LSM 880) and analyzed by LAS AF Lite 3.2.0 Image J 1.74v. IR thermal images were collected by Infrared Camera (Fotric 255). Photoacoustic imaging data was processed by PA Tomography (Vevo LAZR). All other characterization of $\mathrm{TiH}_{1.924}$ was conducted by these instruments as indicated in the Characterization section.

Reporting summary. Further information on research design is available in the Nature Research Reporting Summary linked to this article.

\section{Data availability}

The authors declare that all data needed to evaluate the conclusion of this work are presented in the paper and the Supplementary Information. Other data related to this work are available from the corresponding authors upon reasonable request.

Received: 15 December 2019; Accepted: 3 July 2020;

Published online: 24 July 2020

\section{References}

1. Qian, X., Zheng, Y. \& Chen, Y. Micro/nanoparticle-augmented sonodynamic therapy (SDT): breaking the depth shallow of photoactivation. Adv. Mater. 28, 8097-8129 (2016)

2. Gong, F. et al. Ultrasmall oxygen-deficient bimetallic oxide $\mathrm{MnWO}_{\mathrm{X}}$ nanoparticles for depletion of endogenous GSH and enhanced sonodynamic cancer therapy. Adv. Mater. 31, 1900730 (2019).

3. Lin, X., Song, J., Chen, X. \& Yang, H. Ultrasound activated sensitizers and applications. Angew. Chem. Int. Ed. 59, 2-24 (2020).

4. Pan, X. et al. Metal-organic-framework-derived carbon nanostructure augmented sonodynamic cancer therapy. Adv. Mater. 30, 1800180 (2018)

5. Cui, X., Han, X., Yu, L., Zhang, B. \& Chen, Y. Intrinsic chemistry and design principle of ultrasound-responsive nanomedicine. Nano Today 28, 100773 (2019).

6. Huang, P. et al. Metalloporphyrin-encapsulated biodegradable nanosystems for highly efficient magnetic resonance imaging-guided sonodynamic cancer therapy. J. Am. Chem. Soc. 139, 1275-1284 (2017).

7. Zhong, X. et al. GSH-depleted $\mathrm{PtCu}_{3}$ nanocages for chemodynamic-enhanced sonodynamic cancer therapy. Adv. Funct. Mater. 30, 1907954 (2020).

8. Xu, Z.-Y. et al. The ABCG2 transporter is a key molecular determinant of the efficacy of sonodynamic therapy with Photofrin in glioma stem-like cells. Ultrasonics 53, 232-238 (2013).

9. $\mathrm{Xu}, \mathrm{H} .-\mathrm{N}$. et al. Preparation and sonodynamic activities of water-soluble tetraa-(3-carboxyphenoxyl) zinc (II) phthalocyanine and its bovine serum albumin conjugate. Ultrason. Sonochem. 22, 125-131 (2015).

10. Wang, J. et al. Detection and comparison of reactive oxygen species (ROS) generated by chlorophyllin metal ( $\mathrm{Fe}, \mathrm{Mg}$ and $\mathrm{Cu}$ ) complexes under ultrasonic and visible-light irradiation. Ultrason. Sonochem. 18, 1028-1034 (2011).

11. Pang, X., Xu, C., Jiang, Y., Xiao, Q. \& Leung, A. W. Natural products in the discovery of novel sonosensitizers. Pharmacol. Ther. 162, 144-151 (2016).

12. Lin, H. et al. A single-step multi-level supramolecular system for cancer sonotheranostics. Nanoscale Horiz. 4, 190-195 (2018).

13. Deepagan, V. et al. Long-circulating $\mathrm{Au}-\mathrm{TiO}_{2}$ nanocomposite as a sonosensitizer for ROS-mediated eradication of cancer. Nano Lett. 16, 6257-6264 (2016)

14. Han, X. et al. Oxygen-deficient black titania for synergistic/enhanced sonodynamic and photoinduced cancer therapy at near infrared-II biowindow. ACS Nano 12, 4545-4555 (2018).

15. Wang, X. et al. Site-specific sonocatalytic tumor suppression by chemically engineered single-crystalline mesoporous titanium dioxide sonosensitizers. $J$. Mater. Chem. B 5, 4579-4586 (2017).

16. Ozawa, K. et al. Electron-hole recombination time at $\mathrm{TiO}_{2}$ single-crystal surfaces: Influence of surface band bending. J. Phys. Chem. Lett. 5, 1953-1957 (2014).

17. Murdoch, M. et al. The effect of gold loading and particle size on photocatalytic hydrogen production from ethanol over $\mathrm{Au} / \mathrm{TiO}_{2}$ nanoparticles. Nat. Chem. 3, 489 (2011).

18. Lu, J., Choi, Y. J., Fang, Z. Z., Sohn, H. Y. \& Rönnebro, E. Hydrogen storage properties of nanosized $\mathrm{MgH}_{2}-0.1 \mathrm{TiH}_{2}$ prepared by ultrahigh-energy-highpressure milling. J. Am. Chem. Soc. 131, 15843-15852 (2009).

19. Choi, Y. J., Xu, Y., Shaw, W. J. \& Rönnebro, E. C. Hydrogen storage properties of new hydrogen-rich $\mathrm{BH}_{3} \mathrm{NH}_{3}$-metal hydride $\left(\mathrm{TiH}_{2}, \mathrm{ZrH}_{2}\right.$, $\mathrm{MgH}_{2}$, and/or $\mathrm{CaH}_{2}$ ) composite systems. J. Phys. Chem. C. 116, 8349-8358 (2012).

20. Banhart, J. Light-metal foams-History of innovation and technological challenges. Adv. Eng. Mater. 15, 82-111 (2013).

21. Orovčík, L. et al. Effect of the $\mathrm{TiH}_{2}$ pre-treatment on the energy absorption ability of 6061 aluminium alloy foam. Mater. Lett. 148, 82-85 (2015).

22. Joshi, V. V. et al. Development of Ti-6Al-4V and Ti-1Al-8V-5Fe alloys using low-cost $\mathrm{TiH}_{2}$ powder feedstock. J. Mater. Eng. Perform. 22, 995-1003 (2013).

23. Oh, J.-M., Heo, K.-H., Kim, W.-B., Choi, G.-S. \& Lim, J.-W. Sintering properties of Ti-6Al-4V alloys prepared using $\mathrm{Ti} / \mathrm{TiH}_{2}$ powders. Mater. Trans. 54, 119-121 (2013).

24. Zhang, Y. et al. Surface characterizations of $\mathrm{TiH}_{2}$ powders before and after dehydrogenation. Appl. Surf. Sci. 410, 177-185 (2017).

25. Habisreutinger, S. N., Schmidt-Mende, L. \& Stolarczyk, J. K. Photocatalytic reduction of $\mathrm{CO}_{2}$ on $\mathrm{TiO}_{2}$ and other semiconductors. Angew. Chem. Int. Ed. 52, 7372-7408 (2013).

26. Wang, M., Ioccozia, J., Sun, L., Lin, C. \& Lin, Z. Inorganic-modified semiconductor $\mathrm{TiO}_{2}$ nanotube arrays for photocatalysis. Energy Environ. Sci. 7, 2182-2202 (2014).

27. Coleman, J. N. et al. Two-dimensional nanosheets produced by liquid exfoliation of layered materials. Science 331, 568-571 (2011).

28. Hernandez, Y. et al. High-yield production of graphene by liquid-phase exfoliation of graphite. Nat. Nanotechnol. 3, 563 (2008).

29. Nicolosi, V., Chhowalla, M., Kanatzidis, M. G., Strano, M. S. \& Coleman, J. N. Liquid exfoliation of layered materials. Science 340, 1226419 (2013). 
30. Hanlon, D. et al. Liquid exfoliation of solvent-stabilized few-layer black phosphorus for applications beyond electronics. Nat. Commun. 6, 8563 (2015).

31. Shen, J. et al. Liquid phase exfoliation of two-dimensional materials by directly probing and matching surface tension components. Nano Lett. 15, 5449-5454 (2015).

32. Coleman, J. N. Liquid-phase exfoliation of nanotubes and graphene. $A d v$. Funct. Mater. 19, 3680-3695 (2009).

33. Nguyen, E. P. et al. Investigation of two-solvent grinding-assisted liquid phase exfoliation of layered $\mathrm{MoS}_{2}$. Chem. Mater. 27, 53-59 (2014).

34. Sandim, H. R. Z., Morante, B. V. \& Suzuki, P. A. Kinetics of thermal decomposition of titanium hydride powder using in situ high-temperature Xray diffraction (HTXRD). Mater. Res 8, 293-297 (2005).

35. Aydin, C. et al. Determination of optical band gap of $\mathrm{ZnO}: \mathrm{ZnAl}_{2} \mathrm{O}_{4}$ composite semiconductor nanopowder materials by optical reflectance method. J. Electroceram. 31, 265-270 (2013).

36. Abdullahi, S. S., Güner, S., Musa, Y.K.I.M., Adamu, B.I. \& Abdulhamid, M.I. Simple method for the determination of band gap of a nanopowdered sample using kubelka munk theory. J. Niger. Assoc. Math. Phys. 35, 241-246 (2016).

37. Shanga, X., Lia, B., Zhanga, T., Lib, C. \& Wanga, X. Photocatalytic degradation of methyl orange with commercial organic pigment sensitized $\mathrm{TiO}_{2}$. Procedia Environ. Sci. 18, 478-485 (2013).

38. Swetha, S., Santhosh, S. \& Geetha, R. B. Synthesis and comparative study of nano- $\mathrm{TiO}_{2}$ over Degussa P-25 in disinfection of water. Photochem. Photobio. 86, 628-632 (2010).

39. Liu, B., Wen, L. \& Zhao, X. The photoluminescence spectroscopic study of anatase $\mathrm{TiO}_{2}$ prepared by magnetron sputtering. Mater. Chem. Phys. 106, 350-353 (2007).

40. Zaanen, J., Sawatzky, G. \& Allen, J. Band gaps and electronic structure of transition-metal compounds. Phys. Rev. Lett. 55, 418 (1985).

41. Tanaka, A., Hashimoto, K. \& Kominami, H. Visible-light-induced hydrogen and oxygen formation over $\mathrm{Pt} / \mathrm{Au} / \mathrm{WO}_{3}$ photocatalyst utilizing two types of photoabsorption due to surface plasmon resonance and band-gap excitation. J. Am. Chem. Soc. 136, 586-589 (2014).

42. Khan, M. A., Akhtar, M. S., Woo, S. I. \& Yang, O.-B. Enhanced photoresponse under visible light in $\mathrm{Pt}$ ionized $\mathrm{TiO}_{2}$ nanotube for the photocatalytic splitting of water. Catal. Commun. 10, 1-5 (2008).

43. Irie, H., Washizuka, S. \& Hashimoto, K. Hydrophilicity on carbon-doped $\mathrm{TiO}_{2}$ thin films under visible light. Thin. Solid. Films. 510, 21-25 (2006).

44. Lin, H., Gao, S., Dai, C., Chen, Y. \& Shi, J. A two-dimensional biodegradable niobium carbide (MXene) for photothermal tumor eradication in NIR-I and NIR-II biowindows. J. Am. Chem. Soc. 139, 16235-16247 (2017).

45. Robinson, J. T. et al. Ultrasmall reduced graphene oxide with high nearinfrared absorbance for photothermal therapy. J. Am. Chem. Soc. 133, 6825-6831 (2011).

46. Fang, C.-Y., Chang, C.-C., Mou, C.-Y. \& Chang, H.-C. Preparation and characterization of ion-irradiated nanodiamonds as photoacoustic contrast agents. J. Nanosci. Nanotechnol. 15, 1037-1044 (2015).

47. Zeng, J., Goldfeld, D. \& Xia, Y. A plasmon-assisted optofluidic (PAOF) system for measuring the photothermal conversion efficiencies of gold nanostructures and controlling an electrical switch. Angew. Chem. Int. Ed. 52, 4169-4173 (2013).

48. Hessel, C. M. et al. Copper selenide nanocrystals for photothermal therapy. Nano Lett. 11, 2560-2566 (2011).

49. Tian, Q. et al. Hydrophilic $\mathrm{Cu}_{9} \mathrm{~S}_{5}$ nanocrystals: a photothermal agent with a $25.7 \%$ heat conversion efficiency for photothermal ablation of cancer cells in vivo. ACS Nano 5, 9761-9771 (2011).

50. Cai, X. et al. A versatile nanotheranostic agent for efficient dual-mode imaging guided synergistic chemo-thermal tumor therapy. Adv. Funct. Mater. 25, 2520-2529 (2015).

51. Wu, C. et al. Biodegradable Fe(III)@WS 2 -PVP nanocapsules for redox reaction and TME-enhanced nanocatalytic, photothermal, and chemotherapy. Adv. Funct. Mater. 29, 1901722 (2019).

52. Fisher, J. W. et al. Photothermal response of human and murine cancer cells to multiwalled carbon nanotubes after laser irradiation. Cancer Res. 70, 9855-9864 (2010).

53. Baumgart, J. et al. Off-resonance plasmonic enhanced femtosecond laser optoporation and transfection of cancer cells. Biomaterials 33, 2345-2350 (2012).

54. Gomes, A., Fernandes, E. \& Lima, J. L. Fluorescence probes used for detection of reactive oxygen species. J. Biochem. Biophys. Methods 65, 45-80 (2005).

55. Brown, J. M. \& Wilson, W. R. Exploiting tumour hypoxia in cancer treatment. Nat. Rev. Cancer 4, 437 (2004).
56. Ding, $\mathrm{H}$. et al. Photoactivation switch from type II to type I reactions by electron-rich micelles for improved photodynamic therapy of cancer cells under hypoxia. J. Controlled Release 156, 276-280 (2011).

57. $\mathrm{Hu}, \mathrm{Y}$.-L. et al. Hypoxia-induced autophagy promotes tumor cell survival and adaptation to antiangiogenic treatment in glioblastoma. Cancer Res. 72, 1773-1783 (2012).

58. Shen, S. et al. Bottom-up preparation of uniform ultrathin rhenium disulfide nanosheets for image-guided photothermal radiotherapy. Adv. Funct. Mater. 27, 1700250 (2017).

59. Li, X., Kwon, N., Guo, T., Liu, Z. \& Yoon, J. Innovative strategies for hypoxictumor photodynamic therapy. Angew. Chem. Int. Ed. 57, 11522-11531 (2018)

60. Song, G. et al. Core-shell $\mathrm{MnSe} @ \mathrm{Bi}_{2} \mathrm{Se}_{3}$ fabricated via a cation exchange method as novel nanotheranostics for multimodal imaging and synergistic thermoradiotherapy. Adv. Mater. 27, 6110-6117 (2015)

61. Song, X., Feng, L., Liang, C., Yang, K. \& Liu, Z. Ultrasound triggered tumor oxygenation with oxygen-shuttle nanoperfluorocarbon to overcome hypoxiaassociated resistance in cancer therapies. Nano Lett. 16, 6145-6153 (2016).

62. Zhu, W. et al. Modulation of hypoxia in solid tumor microenvironment with $\mathrm{MnO}_{2}$ nanoparticles to enhance photodynamic therapy. Adv. Funct. Mater. 26, 5490-5498 (2016).

\section{Acknowledgements}

This article was partially supported by the National Basic Research Programs of China (973 Program) (2016YFA0201200), the National Natural Science Foundation of China (51525203, 51761145041, 51572180), Collaborative Innovation Center of Suzhou Nano Science and Technology, a Jiangsu Natural Science Fund for Distinguished Young Scholars (BK20170063), and a Project Funded by the Priority Academic Program Development (PAPD) of Jiangsu Higher Education Institutions. L.C. was supported by the Tang Scholarship of Soochow University. In particular, we sincerely thank Hainertec (Suzhou) Co., Ltd. for providing the ultrasonic generator.

\section{Author contributions}

Z.L. oversaw all research; Z.L., L.C., and F.G. designed the experiments; L.C. and F.G. synthesized the materials; F.G., N.Y., and Y.G. performed the sonodynamic and photothermal experiments; F.G., Y.N., and S.B. performed the cells experiments; F.G., X.W., M.C., and Q.C. performed animal experiments; Z.L., L.C., and F.G. wrote the paper; All authors reviewed and edited the paper.

\section{Competing interests}

The authors declare no competing interests.

\section{Additional information}

Supplementary information is available for this paper at https://doi.org/10.1038/s41467 020-17485-x.

Correspondence and requests for materials should be addressed to L.C. or Z.L.

Peer review information Nature Communications thanks Jae Hyung Park and the other anonymous reviewer(s) for their contribution to the peer review of this work. Peer reviewer reports are available.

Reprints and permission information is available at http://www.nature.com/reprints

Publisher's note Springer Nature remains neutral with regard to jurisdictional claims in published maps and institutional affiliations.

Open Access This article is licensed under a Creative Commons Attribution 4.0 International License, which permits use, sharing, adaptation, distribution and reproduction in any medium or format, as long as you give appropriate credit to the original author(s) and the source, provide a link to the Creative Commons license, and indicate if changes were made. The images or other third party material in this article are included in the article's Creative Commons license, unless indicated otherwise in a credit line to the material. If material is not included in the article's Creative Commons license and your intended use is not permitted by statutory regulation or exceeds the permitted use, you will need to obtain permission directly from the copyright holder. To view a copy of this license, visit http://creativecommons.org/ licenses/by/4.0/

(C) The Author(s) 2020 